\title{
$\mathbf{N}^{\circ} \mathbf{2 0 0 3 - 1 0}$
}

\section{The Heterogeneity of Employment Adjustment Across Japanese Firms. A Study Using Panel Data ${ }^{1}$.}

\author{
Christophe HURLIN, Sébastien LECHEVALIER
}

\author{
Christophe HURLIN \\ Université d'Orléans, CEPREMAP \\ 142, rue du Chevaleret 75013 Paris \\ christophe.hurlin@ecepremap.cnrs.fr
}

\author{
Sébastien LECHEVALIER \\ EHESS, CEPREMAP \\ 142, rue du Chevaleret 75013 Paris \\ sebastien.lechevalier@cepremap.cnrs.fr
}

Internet : Consulter le Web : http://www.cepremap.cnrs.fr

\footnotetext{
${ }^{1}$ We are sincerely grateful to professors Uni Hiroyuki (Kyoto University), Suzuki Hiromasa (Waseda University) and Hirota Isao (Tokyo University) for providing us the access to the NEEDS-FQ database. We also wish to thank Michel Juillard and Yvan Guichaoua for helpful comments. As far as the second author is concerned, financing support by French Ministry of Foreign Affairs (Lavoisier Funding program) and by the Japanese Institute of Labour is greatly acknowledged. All the data and programs used in this article are available on the website http://www.cepremap.cnrs.fr.
} 



\title{
The Heterogeneity of Employment Adjustment Across Japanese Firms. A Study Using Panel Data. Christophe HURLIN, Sébastien LECHEVALIER
}

\begin{abstract}
Since the beginning of the 1990s, there has been a sharp debate in Japan on the end of lifetime employment. On one side, case studies show the intensity of restructuring and downsizing. On the other side, most of the studies on the employment adjustment at a macro level conclude to the absence of change.

This article contributes to this debate, using an original micro database. The first specificity of this paper is to focus on the electrical machinery sector in a panel framework. The current restructuring in this sector is indeed often analyzed as the sign of the changing employment adjustment and, more generally, of the employment system. The second specificity is to consider a long enough period to make a comparison between the 1990 s and the 1970 s.

The first major result is the increasing heterogeneity of the speed of employment adjustment at the level of the firms. Thus, we can explain the contradictory evaluation of the change of the mean speed and disentangle the micro-macro paradox. The second main result concerns the analysis of the characteristics of the firms affecting the speed of adjustment and the factors at the root of the increasing heterogeneity. The model of adjustment seems to have changed: the size tends to play a decreasing role, while the financial characteristics, like the intensity of the link with the Main Bank, are more and more important. Last but not least, the role of these financial factors may be the main explanation of the increasing heterogeneity of the employment adjustment. This last result has however to be confirmed and specified by future studies.
\end{abstract}

\section{L'hétérogénéité de l'ajustement de l'emploi des firmes japonaises. Une étude sur données de panel. Christophe HURLIN, Sébastien LECHEVALIER}

\begin{abstract}
Résumé
Dans le débat sur la fin de l'emploi à vie au Japon depuis le début des années 1990, on note une contradiction croissante entre, d'un côté, les études de cas, qui témoignent d'intenses restructurations, et de l'autre côté, les études sur l'ajustement de l'emploi au niveau macro qui concluent à l'absence de rupture du point de vue de la vitesse d'ajustement.

Cet article est une contribution à ce débat, en reposant sur le recours à une base de données originale. Une première spécificité de ce papier est de se concentrer, dans un cadre de panel, sur le secteur clef de l'électronique, dont la restructuration en cours est souvent présentée comme le signe du changement du mode d'ajustement de l'emploi et plus généralement du système d'emploi. La seconde caractéristique est de considérer une dimension temporelle suffisamment étendue pour permettre une comparaison entre les années 1990 et les années 1970.

Un premier résultat important est l'hétérogénéité croissante de la vitesse de l'ajustement de l'emploi au niveau des firmes, ce qui peut expliquer les évaluations contradictoires de l'évolution de la vitesse moyenne et donc expliquer le paradoxe micro-macro. Un autre résultat important concerne la détermination des caractéristiques des firmes affectant la vitesse mais aussi les facteurs à l'origine de l'hétérogénéité croissante. Le modèle d'ajustement semble avoir changé au cours du temps, avec un rôle moins sensible de facteurs comme la taille et un rôle de plus en plus important des facteurs financiers, comme l'intensité des liens avec la banque principale. Enfin et surtout, ces facteurs financiers semblent à l'origine de l'hétérogénéité croissante des processus d'ajustement de l'emploi.
\end{abstract}

Key words: Panel - Labor Demand - Employment Adjustment - Japanese Employment System. Mots clefs : panel - demande de travail - ajustement de l'emploi - système d'emploi japonais.

JEL Classification : C23, G30, J23, L20, L63, L68. 



\title{
The Heterogeneity of Employment Adjustment in Japanese Firms. A Study Using Panel Data.
}

\author{
Christophe HURLIN, Sébastien LECHEVALIER
}

\section{Contents.}

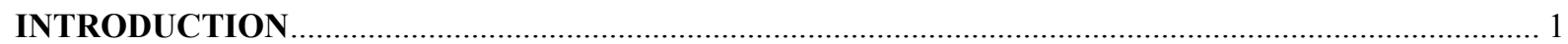

1. The employment adjustment in Japan: stylized facts and hypotheses to be tested............................... 3

1.1 Three stylized facts about employment adjustment in Japan since the beginning of the 1990s................. 3

1.2 The respective influences of financial and non financial factors in the employment adjustment process... 4

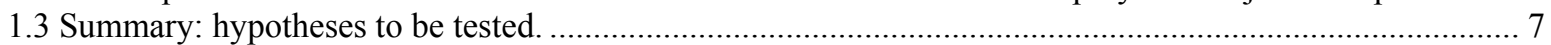

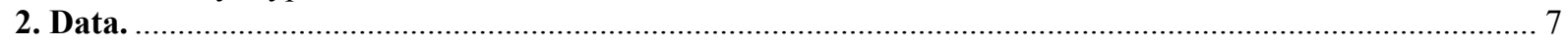

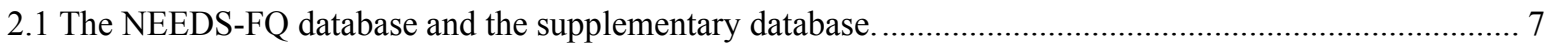

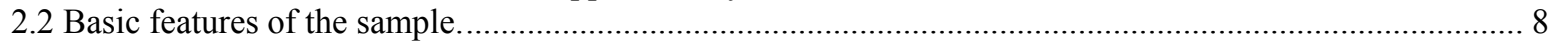

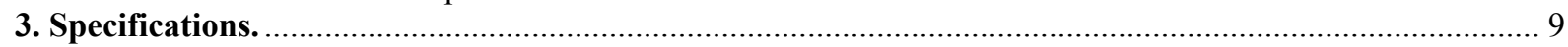

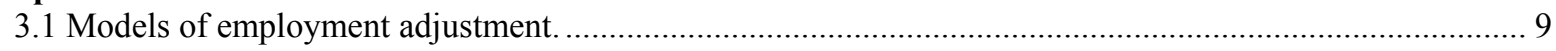

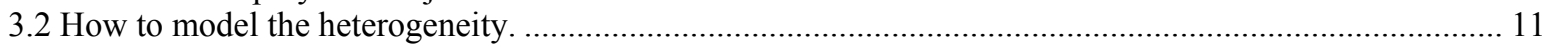

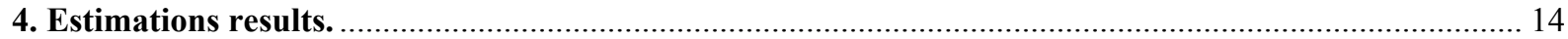

4.1 A lower speed of adjustment in the 1990s than in the 1970s despite an acceleration at the end of the period

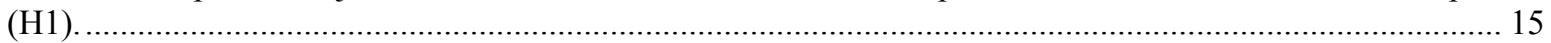

4.2 An increasing heterogeneity in the 1990 s by comparison with the $1970 \mathrm{~s}$ but no proof of a bipolarization of

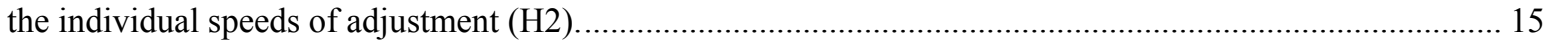
4.3 How to explain the different speeds of employment adjustment at the level of the firms and the increasing

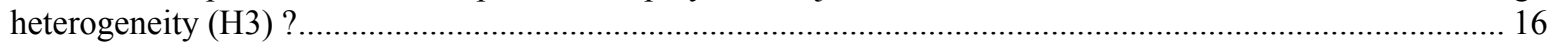

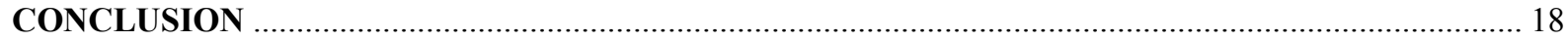

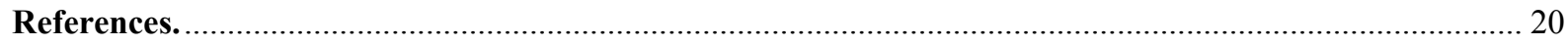

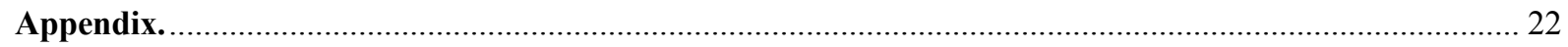

Appendix 1: Dynamics of employment when the costs of adjustment are quadratic...................................22

Figure 1 : Evolution of the speed of employment adjustment to the production between the 1970s and the

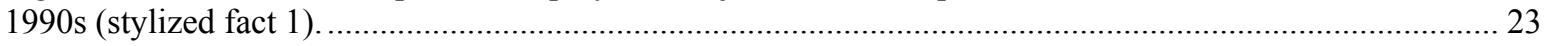

Figure 2: Impact of losses on the speed of adjustment (stylized fact 2) .................................................. 23

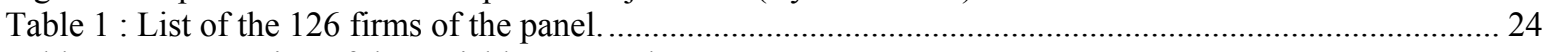

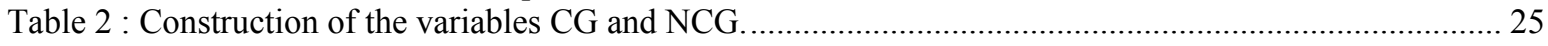

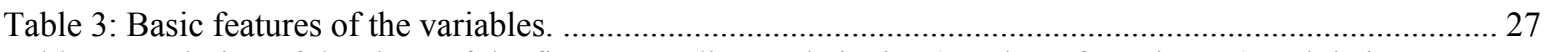

Table 4: Evolution of the share of the firms according to their size (number of employees) and their

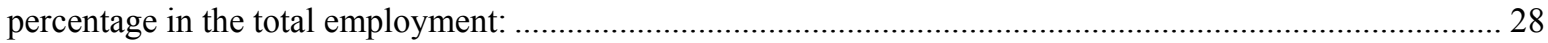

Figure 3 : Evolution of the average size of the firms in 1970 and 2001 (balanced panel of 126 firms)..........28

Figures 4: Profiles of employment adjustment and confrontation to the level of profits.............................29

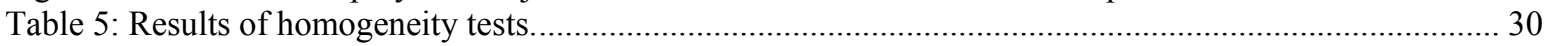

Table 6: Comparison between the estimation firm by firm and the panel estimation with random coefficients

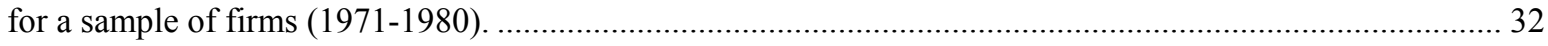

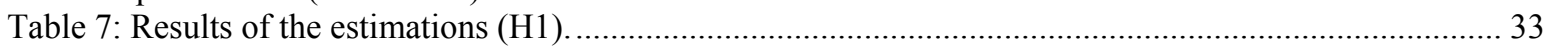

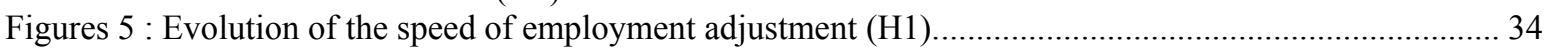

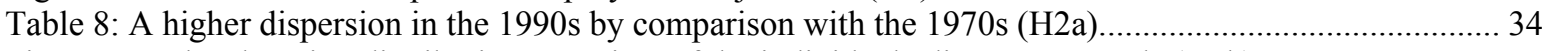

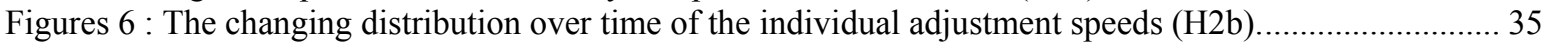

Tables 9: The factors of the heterogeneity of the adjustment speed (H3) ............................................. 37 


\section{INTRODUCTION}

The end of the "Japanese employment system" (JES) has recently become a widely shared idea, in a context of increasing pressures. Indeed, whereas firms responded slowly to macroeconomic and institutional changes since the beginning of the 1990s (Ministry of Labour, 1999), an accelerating adjustment seems to take place since 1998, as the crisis is lasting and maybe worsening. The two pillars of the so-called Japanese employment system are concerned: the seniority wage system and, above all, the compromise on employment security (Lechevalier, 2001). However, there is an increasing gap between the statements pronounced by the case studies at the micro level, which conclude to dramatic changes, and the macro level analyses, which insist on the global stability of the wage labor nexus. This micro-macro paradox is one of the main results of Boyer \& Juillard (1998).

The 2001 massive restructuring in the electrical machinery sector is one example of these changes and pressures. This is all the more important from the point of view of the analysis of the Japanese employment system that firms belonging to this sector, like Matsushita, are considered to have implemented the so-called lifetime employment in the most accomplished way. Moreover, the electrical machinery sector is particularly affected by contemporary pressures on the employment system, such as the impact of technologies of information and communication (TIC) or globalization.

In this context, the study of the employment adjustment in Japanese firms is a good way to measure the current changes and their determinants ${ }^{2}$. It gives us the opportunity to empirically specify the two alternatives of the preceding debate. More precisely, the issue at stake is to check if the characteristics of the adjustment model, especially the speed, have changed since the beginning of the 1990s. In fact, this question has already been the focus of many empirical works. A first type of study has been conducted at the industry and macro levels (Abraham \& Houseman, 1989; Hashimoto, 1993; Boyer \& Juillard, 1998). The basic results can be summarized as follows: 1) the adjustment speed in Japan is slower than in the US, whatever the type of estimates we consider (man-hour-term or man-term); 2) in Japan, the adjustment speed in the first part of the 1990s is slower than in the 1970s. Briefly speaking, these studies do not confirm the alleged end of life-employment system during the 1990s.

More recently, many studies have used firm based micro-data and partially questioned the results obtained at the macro level (Chuma, 2002; Abe, 2002; Suruga, 1998; Hildreth \& Ohtake, 1998) ${ }^{3}$ The main findings are the following: 1) If the path of employment adjustment appears to be continuous and linear at the macro level, it rather seems to be discontinuous and non linear at the micro level. This statement could explain why the adjustments are very rapid and intense under certain conditions, which have to be defined. This may also be at the origin of the micro-macro paradox as defined above: the fact that some firms are restructuring heavily must not be automatically interpreted as the sign of the end of long term employment practices. For example, this is conformed to the "lay-off in last resort" doctrine: the firms adjust slowly until they have no other choice than to resort to lay-offs, which accelerate the

\footnotetext{
${ }^{2}$ This is a good way, but not the sole one. An alternative method is to study the job creations and destructions. The analysis of employment adjustment is preferred here because of a lack of data but also for the purpose of a comparison with the results of classical studies on restructuring in Japanese firms in the 1970s (e.g. Dore et Taira, 1986).

${ }^{3}$ To these references in English, we should add some important references in Japanese, and among other: TOMIYAMA Masayo (2001), The Main Bank System and Employment Adjustment in Firms, The Japanese Journal of Labour Studies, vol. 43, No 2-3; URASAKA Junko \& NODA Tomohiko (2001), The Effect of Corporate Governance on Employment Adjustment in Japanese Manufacturing Firms, The Japanese Journal of Labour Studies, vol. 43, No 2-3; KOMAKI Yoshihiro (1998), Discreteness of Labor Adjustment at Japanese Firms. Analysis Using Panel Data, a Probit Model and a Switching Model, Bank of Japan, working paper.
} 
adjustment process. In these conditions, what needs to be explained is not the slowness of the adjustment but its discrete path; 2) for certain firms, the rule of employment adjustment is influenced by the occurrence of negative profits; 3) non negligible differences in the mode of adjustment are observed across firms, in terms of speed of adjustment, factors at the origin of the employment adjustment and qualitative instruments to adjust employment. This last result leads to put into question the idea of the uniqueness of human resources management (HRM) model in Japan. But it is necessary to go one step further: if there is a multiplicity of adjustment models, the question remains to determine which ones they are. Do we have only two models, one characterized by a low speed of adjustment, representative for the traditional JES, and the other one, with a high speed of adjustment, closer to external flexibility model? Moreover, the questions are to relate these differences of employment adjustment to fundamental characteristics of the firms, to ask whether this heterogeneity across firms has recently increased or not, and finally, in any case, to explain these evolutions.

This question, the heterogeneity of the employment adjustment across firms, is precisely at the center of our own contribution, which consists in deepening the micro type studies. More precisely, we test two conflicting hypotheses: the end of lifetime employment, which can be observed through an identical acceleration of the adjustment speed for all firms, versus an increasing heterogeneity of the employment adjustment across firms. Moreover, is this heterogeneity a purely statistical artifact, due to the resort of micro-data? Conversely, if the heterogeneity is real, what are its causes? Here the theoretical predictions are ambiguous. On one side, in a context of internationalization of the Japanese economy, we can expect a twofold process of convergence of the practices of Japanese firms, towards the Anglo-Saxon standards (Kaneko, 2000), and within the Japanese economy. On the other side, the new macroeconomic context, promoting higher competition, could explain an increasing heterogeneity across firms, first concerning their performances, second related to their employment policies; moreover, this impact could last after the end of the long depression (Favereau, 1991). Finally, the financial factors are essential in the dynamics of the Japanese economy since the 1980s. They are also believed to play a key role in the current restructuring process (Boyer \& Yamada, 2000) ${ }^{4}$. However, their impact on the heterogeneity has to be theoretically specified and empirically stated ${ }^{5}$. This is the second goal of our paper.

For this purpose, we resort to the NEEDS-FQ database (Nikkei Economic Electronic Databank System - Financial Quest). It gives micro-data from a sample of 126 firms of the electrical machinery sector on an annual basis from 1970 to 2001 . Thus, our study is at an intermediate level by comparison with the majority of existing micro studies, some focusing on a few firms (Chuma, 2002 ; Suruga, 1998; Hildreth \& Ohtake, 1998), and the others using huge samples of more than 1000 firms, but strictly limited in the temporal dimension and/or in the number of the tested explanatory variables (Abe, 2002). We believe that this intermediate level provides an opportunity to overcome these limits.

More precisely, our study has the following features. First, we use a panel framework to test and analyze the heterogeneity of employment adjustment patterns across firms.

\footnotetext{
${ }^{4}$ This is not the case only in Japan. Kim \& alii (2002) found an increasing heterogeneity of Human Resource Management systems in Korea between 1998 and 2000, which is directly related to the financial crisis, which occured in 1997. Although that the Japanese and Korean financial crisis are quite different, and that our approach of finance is not limited to the crisis, it could be interesting to compare systematically the impact of these two crisis.

${ }^{5}$ We should add this increasing heterogeneity may be not specific to the Japanese employment system. To quote the most representative study, Katz \& Darbishire (2000) showed that, in almost all the countries they studied, the employment patterns of the firms are getting increasingly diverse.
} 
Contrary to the majority of empirical studies we do not limit our analysis to the introduction of individual effects. Rather, we resort to a Bayesian estimation procedure, which yields to (firm-specific) individual forecasts of the parameters of the adjustment process (Hsiao, 1996). To our limited knowledge, this kind of procedure has never been applied in this field of research. Second, we make a comparison between the 1970s and the 1990s. Third, we try to identify the factors at the roots of both the level of employment adjustment and the heterogeneity of this adjustment; we especially focus on the financial factors by controlling firms' characteristics like the size or the industry.

The two main findings of this paper could be summarized as follows. First, the increasing heterogeneity of firms in the 1990s is confirmed from the point of view of their speed of employment adjustment. Moreover, no evidence can be provided about the increase of the average speed of the employment adjustment in the 1990s by comparison with the 1970 s, which is clearly in opposition with the idea of the end of "lifetime employment". Second, the factors of the adjustment speed and of the heterogeneity have changed during the period under review. Furthermore, we suggest that the increasing heterogeneity is mainly related to financial factors, and especially to the intensity of the links with the Main Bank. These factors seem to play a more and more discriminating role, at the expense of very classical factors like the size of the firm or the sector.

This paper is built as follows. In the first part, we present some stylized facts on the employment adjustment in the 1990s. In a second part, we introduce our dataset. In the third part, we describe the different specifications to be estimated. In the fourth part, we present the results of the estimations. A last part is devoted to concluding remarks.

\section{The employment adjustment in Japan: stylized facts and hypotheses to be tested.}

We begin by describing the main features of the employment dynamics in the Japanese firms. Then, we focus on the influence of financial and non financial characteristics of the firms on the employment adjustment process.

\subsection{Three stylized facts about employment adjustment in Japan since the beginning of the 1990s.}

We first summarize some recent studies on employment adjustment in Japan and the stylized facts they basically brought to the fore. The first two stylized facts are the increasing speed of employment adjustment to the production and the increasing sensitivity to operating losses since the end of the 1990s (figures 1 \& 2). We must draw attention to these results. Indeed, until recently, the studies on employment adjustment in Japan found an average speed of employment adjustment less rapid in the 1990s than in the preceding periods. In any case, the average value of the coefficient is $0.3-30 \%$ of the optimal speed - that is half of what is observed in the United States ${ }^{6}$.

The question remains to know if this evolution is structural or due to business cycles. In the former case, it would reveal a change of the adjustment model. The studies at the micro-level also allow answering this question by determining the underlying model of

\footnotetext{
${ }^{6}$ The "optimal speed" is to be understood by reference to a long term target. See Hamermesh (1993) and our $\S 3$ for a more precise explanation.
} 
adjustment. If the adjustment model is discrete and sensitive to the negative profits, more frequent losses will automatically increase the apparent speed of adjustment. Concluding from this that the Japanese employment system is reaching its very limit is to go one step too far. However, an alternative hypothesis is that the sensitivity to operating losses has increased; in this case, the adjustment model has changed, for example in reaction to changes in corporate governance. This is the main finding of a study conducted by the Ministry of Labour (1999).

The third stylized fact is related to the increasing heterogeneity of the Japanese HRM model. This is indeed a common result of many studies. Nevertheless, this is rarely proved or even systematically analyzed. As for the resort to lay-offs or the use of non-regular workforce, an increasing trend at the macro level indeed coexists with an increasing heterogeneity at the micro level. We showed in a previous work that these two practices are concentrated on some firms in the case of the electrical machinery sector (Lechevalier, 2002). Moreover an increasing heterogeneity of the corporate results is observed: an increasing number of bankruptcies take place at the same time of records of profit for some firms.

The remaining questions concern the nature of this heterogeneity. Did it pre-exist or has it only been revealed by the crisis? How many categories does it encompass: is it a pure diversity or does it correspond to a sort of bipolarization? Finally, what are the underlying factors? This is the object of the following point.

\subsection{The respective influences of financial and non financial factors in the employment adjustment process.}

How to explain the differences of speeds of employment adjustment across firms from a structural point of view? Here, two questions appear. The first one concerns the determinants of the employment adjustment speed and the second the factors at the root of the increasing heterogeneity, as stated above. Among the potential explanatory factors, it may be practical to distinguish between the financial and the non financial ones.

Among the latter, the most commonly acknowledged are the industry and the size. Many studies have already found significant differences of speed across industries (Abraham \& Houseman, 1989; Abe, 2002). Here we control the sector and look for other explanatory variables. However, within the electrical machinery sector, which is heteroclite by nature, we can expect to observe different models of adjustment according to the main activity of the firm (white electronic, hardware, software, etc.). Regarding the size, it a priori slows down the speed of adjustment (Hashimoto, 1993). Indeed, the bigger a firm is, the more it can resort to internal transfers of a part of the workforce, which is not accounted in our study. This is due to our definition of the employment speed, which focuses on the external mobility.

Other non financial factors may affect the employment dynamics. First of all, the share of export in the total sales captures the impact of the globalization of product markets on the employment from the point of view of the firms. This export ratio is expected to contribute to a more rapid adjustment (Dore \& Taira, 1986). Second, the innovation effort (as captured by the ratio of $R \& D$ expenses) and the capital intensity should have a negative impact on the speed. This is the main result of a "labor as a quasi fixed factor" type of analysis (Oï, 1962): the more the firm is oriented toward innovation and the more it is capital intensive, the more the human capital is integrated to the physical capital and is the object of specific investments. Two other (non technological) factors are the union rate, with an expected negative impact on the speed (Hashimoto, 1993), and the average age of the employees, which is an indication of the job tenure, when there are few mid-career recruitments and when the growth rate is moderate (Tachibanaki \& Taki, 2000) ${ }^{7}$. The impact of this last variable may change over time

\footnotetext{
${ }^{7}$ This is not the case for all the firms from our sample: in some cases, the workforce is multiplied by more than three during the period 1971-2001. Most of these recruitments concerned people under the age of 30 .
} 
and is a good indicator of the orientation of the employment policy of the firms. For example, the change of the impact, from negative in a first period to positive in a second period could be interpreted as the sign of the end of lifetime employment. It would mean that this practice reached its own limits and the firms took another option. Another group of variables allows us to characterize what could be called the "history of the firm". This is basically the duration of the existence of the firm, which has a negative impact on the speed of adjustment: the older the firm is, the slower it adjusts the employment (Chuma, 2002) ${ }^{8}$. We add two variables, which are taken from the typology established by Chuma (2002): they indicate if the firms have already experienced in the past (that is before the current restructuring) operating losses and / or downsizing. These experiences may have an influence on the current practices: two firms, with equivalent losses in the current period, are expected to react differently according to their past experiences. Finally, let us mention a last group of variables, which are of importance but won't be introduced in the estimations because of a lack of available data. They are the market's share of the firm (as in Dormont (1996), with a negative impact on the employment speed), the level of education of the employees (which is expected to slow down the speed, according to a human capital argument), the degree of diversification of the firm's production (the more diversified it is, the slower is the speed, because of the possibility of managing with the business cycles and of employees transfers across sections), the fact to belong or not to a group, may it be of keiretsu type or not, with the same effect as the preceding variable, for the same reason (Sako \& Sato, 1997).

In addition to the above mentioned non financial factors, our study will bring a closer focus on the financial factors. We justify this perspective by the fact that our theoretical approach is inspired by the ideas of complementarity between financial and employment contracts (Garvey \& Swan, 1992). Moreover, the corporate finance has experienced drastic changes for more than 20 years, if we consider the long process of deregulation, the Bubble and the consequences of its burst, which are still lasting (Hoshi \& Kashyap, 2001). Furthermore, the debate about the evaluation of the impact of these changes on the employment relation has not yet come to an end ${ }^{10}$. Thus, one of our starting points is the above mentioned stylized fact concerning the increasing sensitivity of employment to operating losses. This is considered as a potential transmission channel of the changes, which occurred in the financial sphere, to the employment system. In fact, recent examples of downsizing (e.g. Nissan) showed the importance of financial factors. Finally, in a previous work, we have put forward the following hypothesis: since the 1980s, in a context of deregulation, the Japanese firms faced new opportunities of financing their investment, and their recourse to these opportunities vary greatly. This is a factor of heterogeneity, which may be compared to the differentiated use of foreign technologies in the 1910-1920s, recognized as one of the roots of the dual structure, 30 years later (Lechevalier, 2003). In this paper, one of our goals is therefore to test this hypothesis and to check, among the financial factors, which one had the most important impact.

Consequently, it will induce a decrease of the average age of the employees, even if the firm has a long term employment policy. Generally speaking, the age and the job tenure have to be distinguished, especially when they are considered as explanatory variables of wages, for example. However, in the case of our study, in the absence of any information on the job tenure, the average age can be used with caution as an indication of the practices of long term employment.

${ }^{8}$ In our study, we will consider respectively the dates of creation of the firm and of its first listing on the stock exchange, which are expected to have a positive impact on the adjustment speed, for the same reasons.

${ }^{9}$ What is analyzed from a non consolidated point of view as external mobility between two firms from the same group, is considered as internal mobility from a consolidated point of view. Thus, it does not appear in the type of study we conduct. However, we do resort only to non consolidated data, so that this is not an issue for us.

${ }^{10}$ For example, despite that they opt for the same institutionalist theoretical framework, Lazonick (1998) on one side and Boyer \& Yamada (2000) on the other side, find opposite results. The former minimize the impact of the changes that occurred in finance while the latter detect a breakdown of the trend. 
We will investigate the impact of different categories of financial variables: those "traditionally" considered as representative of the Japanese style of corporate governance as analyzed by Aoki (the Main Bank; the financing structure, with the opposition between markets and banks; the stockholding structure), and those relative to the performance (Return on Assets) and the financial status (mainly debt). We first consider the impact of the Main Bank. The empirical literature questions (if not invalidates) the classical theoretical analysis of its role (Miwa, 1996; Kaneko, 2001). Indeed, the intervention of the Main Bank may accelerate the speed of adjustment in a firm, whose investment in human capital is weak, whereas it can slow it down in a firm, which puts the accent on its human resources ${ }^{11}$. Another important variable is the financing structure in itself. The reality is much more complicated than the theoretical opposition between market-led and bank-led financing. A bank itself facing difficulties (as has been common since the beginning of the 1990s) and impatient market investors will have the same impact on the adjustment speed ${ }^{12}$. In these conditions, the most appropriate criterion may be the degree of dependence on the main financing source. In this case, the firms, whose financing is more balanced between market and bank, may have an employment situation, which is less sensitive to the financial status, and thus a slower speed of adjustment. The last "classical" variable is the stockholding structure, which can be sub-divided itself into at least four aspects (Abe, 2002). One is the cross-shareholding, which is expected to have a negative influence on the employment adjustment, according to a classical argument related to the Japanese style of corporate governance (Aoki, 1990). Another one is the concentration of the shareholding, which may also slow down the speed, according to an argument of stability and long term perspective of the shareholders (Abe, 2002). As for the foreign owners, it is interesting to introduce an indicator of their share to catch the degree of internationalization of the firm ${ }^{13}$. Potentially less important but of interest is the listing market (or the absence of listing): for a given size, a listed firm (particularly on the first market) will face a stronger pressure than a firm, which is non listed or listed on the second market (Horiuchi, 1995) ${ }^{14}$.

To these "classical" factors, we may add two sets of variables, partly ignored by most of the empirical studies on the link between finance and employment. The first one is the performance, for which we have many indicators. Even if it is difficult to evaluate the direction of the causality, convergent results indicate a significant and negative sign (e.g. Okazaki, 1995): in other words, good performances go hand in hand with a slow employment adjustment. The second one concerns the financial status, that is, mainly, the debt, which has to be distinguished from the financing structure. The Bubble period, which can be specifically extended to the 1990s for one part of the electrical machinery sector in the context of the socalled "New Economy", lead to over-investment and over debt behaviours for some firms. After the burst of the Bubble, the consequences of such strategies have been dramatic, especially in a deflationary context, which increased the burden of the debt. In fact, according to a study realized by the Development Bank of Japan, the Debt Equity Ratio (DER) accelerated significantly the process of job destructions in Japan between 1978 and 1998. The

\footnotetext{
${ }^{11}$ On this point, see Tomiyama (2001). The definition of the Main Bank is itself ambiguous, as can be seen at the empirical level. In the appendix we specify our definition of the Main Bank.

${ }^{12}$ See Tomiyama (2001).

${ }^{13}$ As recognized by Boyer \& Yamada (2000), there is a potential link between the export ratio, which increased for some firms since the 1970s, and the share of foreign investors, which increased one decade later for the same firms. Our framework allows us to test this hypothesis.

${ }^{14}$ All the 126 firms of our sample are listed on the first or on the second market in 2001, but some of them were not at the beginning of the period.
} 
author of the study concludes that the influence of the financial status of the firms on the employment adjustment decisions had certainly increased since the $1970 \mathrm{~s}^{15}$.

In the appendix, we explain the construction of the variables we introduced in this article. Before summarizing the hypotheses to be tested, we specify the questions we ask about the respective role of the financial and non financial factors on the employment adjustment. We do not consider that financial factors are the only causes to explain the differences of employment adjustment (question 1); rather we test if they are at the origin of the increasing heterogeneity of the adjustment across firms, if this trend is confirmed (question 2).

\subsection{Summary: hypotheses to be tested.}

Conditionally to a specification of the dynamics of employment adjustment at the micro level, we test a set of three hypotheses:

- H1: Is the average speed of employment adjustment more rapid in the 1990s than in the 1970s?

- H2: Do we observe a bipolarization of the individual speeds of employment adjustment in the 1990s? This hypothesis can be divided into two sub-hypotheses:

- H2a: Is there a higher dispersion of the speed of employment adjustment across firms in the 1990s by comparison with the 1970s?

- H2b: Is it possible to discriminate between different groups of firms (and, at the extreme, between two polarized groups) in the 1990s from the point of view of the dynamics of adjustment?

- H3: How to explain the differences of adjustment speed across firms and, conditionally to the result obtained for $\mathrm{H} 2$, the increasing heterogeneity over time? What are the respective influences of financial and non financial factors? This hypothesis can again be divided in two sub-hypotheses:

- H3a: What are the financial and non-financial variables, which could explain the differences of adjustment speed across firms?

- H3b: Has the impact of financial and non financial variables varied over time?

\section{Data.}

\subsection{The NEEDS-FQ database and the supplementary database.}

In this paper we use a balanced panel of 126 firms, classified in the electrical machinery sector and observed over the period 1970-2001. The 126 firms are listed in table 1. This sample is obtained from the NEEDS-FQ database. This database is built from the annual reports of firms listed at the Tokyo Stock Exchange. Although NEEDS-FQ is a financial oriented database, without precise information about the workforce, except the number of regular employees in the mother-firm, it is increasingly used by scholars to study the patterns of employment adjustment and the characteristics of the corporate governance. Indeed, this is a quite unique accessible source of individual data, the only equivalent being the

\footnotetext{
${ }^{15}$ Development Bank of Japan (2000), Job Creation and Job Destruction in Japan, 1978-1998. An Empirical Analysis based on Enterprise Data.
} 
Development Bank of Japan database. It gives the opportunity to overcome the lack of individual data, provided by the Japanese administration.

Our sample has been obtained after eliminating 152 firms from the initial sample (278 firms classified in the electrical machinery sector in 2001). Our sample does not include firms listed before 2001, and which are no longer listed in 2001. Consequently we face a classical problem of survival bias. This problem is aggravated by the fact that firms with missing data during the period $1970-2001$ have been excluded from our panel. As a consequence we don't consider the job creations and destructions through the birth and death of firms. This is all the more a limit of our study that, in particular, we do not take into account the increasing risk of bankruptcy, which has greatly affected the conditions of employment security since the beginning of the $1990 \mathrm{~s}^{16}$.

Another problem to be noted concerns the heterogeneity of the accounting year-end across firms. This problem is even worse for firms, which changed their year-end accounting during the period under review. We have proceeded to a widely used "regularization" procedure by converting the longer period to a full-year basis, for firms that change their fiscal year-end. Doing so, we did not specifically treat the problem of seasonality, which could result in abnormal values ${ }^{17}$.

The data are used on an annual basis (semiannual were also available), because we are focusing on the "long-term" employment adjustment, which takes place every year (Hildreth \& Ohtake, 1998). We resort to the non-consolidated data, which are better than the consolidated one to study a long term evolution between 1971 and 2001 (Suruga, 1998). We have no information about the number of non-regular employees, nor about the worked hours, which are however two important features of the Japanese mode of employment adjustment. Consequently, our results concern uniquely the number of regular employees. A price index for the electrical machinery sector, taken from the Bank of Japan database, has been chosen to value production, understood as sales per annum rather than the value added ${ }^{18}$. Finally, we use the real average wage, constructed by dividing the payroll by the number of employees and deflating by the same price index as the one used for production.

Moreover, we merge a supplementary dataset with the original one. In addition to the NEEDS-FQ, we resort to the following sources: the Spring issue of the Japan Handbook Company (JCH), which is a quarterly review; Keiretsu no Kenkyu (KNK), which is an annual review; the database of Denki Rengo, the main umbrella organization for the electrical machinery sector enterprise-based unions. It allows us to introduce two vectors of variables, CG (corporate governance) and NCG (non corporate governance), respectively built with financial and non financial variables, to explain the heterogeneity of employment adjustment across firms by financial and non financial factors. The definition of the variables and the sources are specified in tables 2 .

\subsection{Basic features of the sample.}

As for the electrical machinery sector, we refer to the usual classification made by the Tokyo Stock Exchange. This is not without ambiguity because the scope of the production of the firms classified in this sector is very wide, from devices to software or white electronics. Another point is that the main activity could have changed during the 31 year long period.

\footnotetext{
${ }^{16}$ The annual number of bankruptcies increased from 6,500 in 1991 to almost 19,000 in 1998 and has since stabilized between 15,000 and 16,000.

${ }^{17}$ Refer to Nakamura (2001) for a very clear exposition of this problem.

18 The results of estimations with production as value added are also available but are less good.
} 
That is why our benchmark is the year 2001. We found equivalent classifications by the Japanese Ministry of Labour and by the Denki Rengo.

The basic features of our data are summed up in table 3. It is possible to highlight the following points. First of all, an increasing heterogeneity of the performances in the 1990s, both in terms of productivity and profitability, can be observed. Moreover, the average productivity is multiplied by almost 3 between the 1970s and the 1980s but by only 2 between the 1980s and the 1990s, while the average operating profit declines in the 1990s after having more than doubled between the 1970s and the 1980s. As for the ROA (Return on Assets) and other profitability indicators, we observe a continuously decreasing trend from the 1970 s to the 1990s. Concerning other financial variables, the average debt, as measured by the DER, increased slightly in the 1990s, while the ratio of the bank debt owned by the Main Bank surprisingly increased from the 1970s to the 1990s. As for the shareholding structure, we can note decreasing trends for the concentration ratio, the cross-shareholding, and increasing trends for the shares owned by financial institutions and foreign firms. Finally, two important non financial variables can be analyzed as follows: the average exports ratio increased from $18,8 \%$ in the 1970 s to $25,5 \%$ in the 1990 s, while the average age of employees increased slightly from the 1970 s to the 1990 s ( +7 years).

We now specify the evolution of employment. The average size of the firms was 5,206 employees in 1970 and is 4,800 in 2001. This change is the result of an evolution in three stages: between 1970 and 1979 the average size decreased; then, until 1992 it increased, before decreasing again (figure 3). On average, during the whole period, the sample covers 600,000 employees. Another point to be mentioned is that the variance of the size decreased in the 1990 by comparison with the 1970s (tables 4). Most of the firms are very large. This is not a problem for our purpose, which is to show an increasing heterogeneity for firms of similar size and within a same sector. Finally, some typical patterns of employment adjustment are reproduced in appendix (figure 4). We can make the following statements. First, one can observe a huge variety of adjustment patterns by comparison with the average industry pattern. Moreover, the profile of adjustment is very much more discontinuous at the micro level (with the exception of very big firms like Hitachi), with annual variations of more than 20\% (e.g. Togami between 1975 and 1976). Finally, the sensitivity of employment to losses varies during the period and across firms: for example, it is less important for Yasukawa in the 1970s by comparison with the 1990s, while it is always lower for Nihon Inter Electronics.

\section{Specifications.}

The choice of the specification is determined by the answers given to two problems: the form of the employment adjustment (continuous versus discrete) and the modelling of the heterogeneity. Our contribution focuses on the second problem. However, here we successively consider these two points.

\subsection{Models of employment adjustment.}

The form of dynamic labor demand depends on the specification of the adjustment costs. A first way to approximate these costs is to consider a quadratic and symmetric function $C\left(\Delta L_{t}\right)$ defined as (Eisner \& Strotz 1963): 


$$
C\left(\Delta L_{t}\right)=\frac{c}{2}\left(L_{t}-L_{t-1}\right)^{2} \quad c>0
$$

This far from perfect specification however allows us to easily derive the analytical form of labor demand. Indeed, assuming a quadratic form for the production function $F\left(X_{t}, L_{t}\right)=X_{t} L_{t}-(b / 2) L_{t}^{2}, b>0$, we can show that in an uncertain environment, under the assumption of rational expectations, the maximization of an expected stream of discounted profits leads to the following form of employment dynamics (see appendix 1) :

$$
L_{t}=\lambda L_{t-1}+\sum_{i=0}^{\infty} \gamma_{i} E_{t}\left(X_{t+i}-w_{t+i}\right)
$$

where $w_{t}$ is the real wage at time $t$ and where the autoregressive parameter $\lambda$ is a non linear combination of the structural parameters:

$$
\lambda=\frac{c+(1+r)(b+c)}{2 c}-\frac{1}{2 c}\left\{[c+(1+r)(b+c)]^{2}-(1+r) c^{2}\right\}^{\frac{1}{2}}
$$

Adding the assumption of a first-order autoregressive form for the exogenous factors $X_{t}$ and for the real wage $w_{t}$, the conditional expectations of these variables are then proportional to the current observed level. We can deduce a labor dynamic demand shown by:

$$
L_{t}=\lambda L_{t-1}+\beta X_{t}+\phi w_{t}
$$

where the parameters $\beta$ et $\phi$ are a non linear combination of the autoregressive parameters of exogenous processes characterized by the parameters $\gamma_{i}$. In this case, we find the same specification as Hamermesh (1993):

$$
L_{t}=\lambda L_{t-1}+\beta Z_{t}+\varepsilon_{t}
$$

where $Z_{t}$ designs a vector of variables influencing the long-run labor demand. In such a specification, all the explanatory variables are observable; moreover, the estimation of the parameter $\lambda$ gives a measure of the speed of employment adjustment, through the median lag defined by $-\log (2) / \log (\lambda)$. Then we can show that the speed of employment adjustment is inversely proportional to the level of adjustment costs represented by the parameter $b$.

From this general specification, we can derive several variants, based on alternative assumptions on the adjustment cost structure, the nature of expectations and the form of the production function. Here, we adopt a framework with one production factor, labor, which is not split into workforce and work hours, because of a lack of data. Finally, we use a log linear approximation of the model without an explicit long-run target:

$$
\log L_{t}=a_{0}+a_{1} \log Q_{t}+a_{2} \log w_{t}+a_{3} \log L_{t-1}+\mu_{t}
$$

where $Q_{t}$ and $w_{t}$ denote respectively the level of production and the real wage. In this case, the "speed" of adjustment is given by $1-a_{3}$. Indeed, the coefficient gives an idea about the duration of the impact of a shock. It can be expressed under the form of a median lag; here, we will use the expression of "speed".

Nevertheless, it is now commonly admitted that the adjustment costs are non symmetrical and non convex (Hamermersh et Pfann 1996). That is why we will consider alternative assumptions to generate non linearity and asymmetry in the employment dynamics. However, in the frame of this article, we won't explicitly specify the adjustment costs structure. More particularly, we consider switching models in using as the switching variable either lagged variables of employment growth rate or exogenous variables: 
Variant 1: model with variable adjustment according to the direction of employment adjustment:

$$
\begin{gathered}
\log L_{t}=a_{0}+a_{1} \log Q_{t}+a_{2} \log \left(W_{t} / P_{t}\right)+a_{4} \log L_{t-1}+\mu_{t} \text { if } L>L_{-1} \\
\log L_{t}=a^{\prime}{ }_{0}+a^{\prime}{ }_{1} \log Q_{t}+a^{\prime}{ }_{2} \log \left(W_{t} / P_{t}\right)+a_{5} \log L_{t-1}+\mu^{\prime}{ }_{t} \text { if } L<L_{-1}
\end{gathered}
$$

Variant 2: negative profit model (Suruga, 1998) :

$$
\begin{gathered}
\log L_{t}=a_{0}+a_{1} \log Q_{t}+a_{2} \log w_{t}+a_{4} \log L_{t-1}+\mu_{t} \text { if } P R_{t}>K \\
\log L_{t}=a^{\prime}{ }_{0}+a^{\prime}{ }_{1} \log Q_{t}+a^{\prime}{ }_{2} \log w_{t}+a_{5} \log L_{t-1}+\mu_{t}{ }_{t} \text { if } P R_{t}<K
\end{gathered}
$$

where $\mathrm{PR}_{\mathrm{t}}$ denotes the profit (operating or current) and $\mathrm{K}$ is a constant.

Variant 3: external labor market conditions model:

$$
\log L_{t}=a_{0}+a_{1} \log Q_{t}+a_{2} \log w_{t}+\left(a_{4}+a_{5} U_{t}\right) \log L_{t-1}+\mu_{t}
$$

where $U_{t}$ denotes the unemployment rate. Thanks to this last general specification, it is possible to introduce miscellaneous variables affecting the adjustment process, without using a switching model, which often gives birth to identification problems.

\subsection{How to model the heterogeneity.}

Now, let us consider the preceding specifications in a panel framework including $N$ firms observed on $T$ periods. For firm $i=1, . ., N$ and year $t=1, . ., T$, the simplest model is the following:

$$
\log L_{i, t}=a_{0}+a_{1} \log Q_{i, t}+a_{2} \log w_{i, t}+a_{3} \log L_{i, t-1}+\varepsilon_{i, t}
$$

In this specification, we assume that the dynamics of employment is strictly identical for all the firms of the sample. Implicitly, it is equivalent to assume the homogeneity of the production structure and of the adjustment costs function ( $b$ and $c$ parameters in the above specifications). In this case, the average median lag is identical for all firms. Such an assumption is in fact very restrictive and has to be tested (Hsiao, 1986).

On the contrary, we can assume that the structure of production and the functions of adjustment costs vary across firms, so that there is nothing common between them, except the general specification of the functions. In that case, the model is:

$$
\log L_{i, t}=a_{0, i}+a_{1, i} \log Q_{i, t}+a_{2, i} \log w_{i, t}+a_{3, i} \log L_{i, t-1}+\varepsilon_{i, t}
$$


where the parameters $a_{j, i}, j=0,1,2,3$ are a priori different across the firms and residual $\varepsilon_{i, t}$ are independently distributed across firms. As a result, these parameters have to be estimated firm by firm.

Between these two extreme assumptions, some specifications provide a better and more general modelling of the heterogeneity of the employment adjustment paths. First of all, we shall consider that the introduction of individual effects is sufficient to take into account the heterogeneity of the dynamics:

$$
\log L_{i, t}=a_{0, i}+a_{1} \log Q_{i, t}+a_{2} \log w_{i, t}+a_{3} \log L_{i, t-1}+\varepsilon_{i, t}
$$

In this case, we assume the heterogeneity across firms of the structural level of employment $E\left(L_{i, t}\right)=a_{0, i} /\left(1-a_{3}\right)$, under the restrictive assumption that the speeds of adjustment and the long term parameters are homogenous. The existence of individual effects has to be tested before the choice of their specification, fixed or random (Hsiao, 1986). However, such assumption is ad hoc because we have seen above that the constants and the coefficients of this specification are non linear combinations of the same structural parameters, if we assume the existence of quadratic adjustment costs and rational expectations. Under these last two assumptions, it is difficult or even impossible to identify a heterogeneity concerning the average levels, without this heterogeneity affecting the autoregressive parameter of the conditioning variables. In the former example, with quadratic production and adjustment costs functions, the constant and the autoregressive parameter are functions of the parameters $b$ and $c$ (see equation 1): if one of these two structural parameters varies across firms, we cannot derive a specific constant for each firm, while keeping the assumption of the same adjustment speed.

In these conditions, a panel specification providing an effective capture of the heterogeneity of the employment dynamics (coming either from the production structure or from the adjustment costs) consists in assuming the existence of random coefficients (Swamy 1970) :

$$
\begin{gathered}
\log L_{i, t}=a_{0, i}+a_{1, i} \log Q_{i, t}+a_{2, i} \log w_{i, t}+a_{3, i} \log L_{i, t-1}+\varepsilon_{i, t} \\
a_{i}=\left(a_{o, i} a_{1, i} a_{2, i} a_{3, i}\right)^{\prime} \text { 'i.i.d. }(\bar{a}, \Omega)
\end{gathered}
$$

where the parameters $a_{j, i}$ and in particular the adjustment speed $a_{3, i}$ are assumed to be real random variables and $\Omega$. Since this specification is not restricted by assuming the equality of the parameters, it allows taking into account the heterogeneity of the adjustment dynamics. However, we assume that these variables have a common distribution, or, at least, two identical first moments of distribution. We then have to estimate the expected value and the second order moments associated to these distributions. Here appears the second advantage of this approach: it gives the possibility to make the estimation on the basis of a distribution of adjustment speeds. For example, it is possible to evaluate the mean and the variance of the distribution from the sample. Doing so, we can precisely measure the increasing or decreasing trends of the heterogeneity of the adjustment median lag across firms.

Nevertheless, this specification with random coefficients raises several problems. First of all, it is necessary to justify the stochastic nature of the parameters of the reduced form. If we come back to the initial model, this hypothesis is equivalent to the ad hoc assumption of 
adjustment costs or production functions with stochastic parameters. However, it is important to note that the general solution for such kinds of functions is no more defined by the equation 1. The second issue with this specification is that we do not have an a priori forecast of the adjustment speed for one particular firm. We can just estimate the first two moments of its distribution. We will solve this problem in proposing a Bayesian estimator of the individual parameters (Hsiao, 1996). We will a priori assume a distribution on these parameters, by using the GLS estimators of the two first moments. The Bayesian predictor we then obtain is a combination of the information specific to each firm $i$ (time series information) and of the $a$ priori information on the first two moments of a distribution, which is assumed to be homogenous for the set of $N$ firms. Thus, for a given firm, the less precise the individual information on the adjustment speed is (that is the higher the variance of the individual estimator is), the closer the individual predictor will be to the mean of the distribution, estimated for the complete sample. On the contrary, in the case of a firm, on whose adjustment speed we have precise individual information, the individual predictor will give a small weight to the information given a priori on the expected value of the distribution common to the firms. More formally, if we note $\hat{a}_{i}$ the Bayesian individual predictor of the vector of parameters $a_{i}$ for the $i^{\text {th }}$ firm we have:

$$
\hat{a}_{i}=\left(\hat{\Delta}^{-1}+\frac{1}{\hat{\sigma}_{i}^{2}} X_{i}^{\prime} X_{i}\right)^{-1}\left(\hat{\Delta}^{-1} \hat{a}+\frac{1}{\hat{\sigma}_{i}^{2}} X_{i}^{\prime} Y_{i}\right)
$$

In this definition, $\hat{a}$ corresponds to the GLS estimate of the mean of the distribution of parameters $a_{i}$, and $\hat{\sigma}_{i}$ denotes the estimate of the variance of residuals for the firm $i$. The Swamy's estimate of the matrix of variance covariance of the parameters $a_{i}$, denoted $\hat{\Delta}$, is defined as:

$$
\hat{\Delta}=\frac{1}{N} \sum_{i=1}^{N}\left(\hat{a}_{i}-\bar{a}\right)^{\prime}\left(\hat{a}_{i}-\bar{a}\right)
$$

where $\hat{a}_{i}$ is the OLS estimate of individual parameters $a_{i}$ and $\bar{a}=(1 / N) \sum_{i=1}^{N} \hat{a}_{i}$.

These Bayesian predictors will be particularly useful in the second step of the study, when we try to explain the differences of the adjustment speed by financial and non financial variables characterizing the firms. Two alternative methods are then possible. The first one is very close to the variant 3 that we presented above: the principle is to introduce directly the vectors CG and NCG in the equation of employment adjustment. For example this is the route followed by Abe (2002) ${ }^{19}$. In this specification, it is necessary to identify ex ante all the explanatory variables of the heterogeneity of the adjustment speed and to know the functional form linking this speed to the explanatory variables. Consequently this method is sensitive to the specification mistakes. This limit is overcome when we consider a second method, whose principle is to regress the Bayesian predictors on the CG and NCG vectors:

$$
\hat{a}_{3, i}=\theta_{0, i}+\theta_{1, i} C G_{i}+\theta_{2, i} N C G_{i}+\xi_{i}
$$

where $\hat{a}_{3, i}$ denotes an individual predictor of the parameter $a_{3, i}$. The advantage of this method is to get results on the influence of financial and non financial variables not only on the adjustment speed but also on the heterogeneity of this speed and of the underlying model. It is then possible to distinguish different groups of firms.

\footnotetext{
${ }^{19}$ In fact, this is the most current method of estimation, used in the majority of the studies. It allows checking if a given variable has an influence on the adjustment, but it does not allow distinguishing this impact across the firms.
} 


\section{Estimations results.}

The results of estimations are reproduced in table 7 (H1 hypothesis). The first point concerns the results of the homogeneity tests (tables 5). Whatever the specification we consider, the best approach of the heterogeneity is the one with random individual effects. This is confirmed by the results reported in table 7: the better heterogeneity is modelled, the closer to the expected value are the estimated coefficients ${ }^{20}$. As a benchmark, we propose a comparison between two extreme assumptions, the pooled specification (same model for all the firms) and the estimation firm by firm (indi). The former is rejected by the homogeneity tests, even if the results improve when the estimation is conducted by sub-periods ${ }^{21}$. Besides, the estimated coefficients are very different from the expected value. As much as the latter is concerned, it is confirmed by the homogeneity tests. But it raises unsolvable problems for estimations by sub-periods, because of a lack of observations. This is the main reason to justify the choice of a panel frame with random coefficients, which is the less restrictive assumption from the point of view of the heterogeneity.

The log-linear fixed coefficients specifications, with or without fixed individual effects, were estimated through Ordinary Least Squares (Pooled and Within Estimators). Naturally, the introduction of fixed individual effects in a dynamic specification induces a small sample bias (Nickell 1981). Moreover, Judson \& Owen (1999) showed by simulation that these biases are not insignificant (around 30\%), especially for panels with 30 points in the temporal dimension. Although this is the case of our estimation, we used this method because the estimated value for the speed of adjustment is reduced when the heterogeneity is better taken into account. In table 6 , we compare the estimation firm by firm with the estimation with random coefficients: the outlier results are systematically improved.

The parameters of the random coefficients specifications (mean and variancecovariance matrix of the distribution of the coefficients) are estimated by following the method proposed by Swamy (1970). An estimator of the variance-covariance matrix of the coefficients is first built based on $N$ individual estimators of the parameters obtained equation by equation. Then, by using this estimator of the variance-covariance matrix of the parameters, we build a variance-covariance matrix of the residuals, thanks to which we construct a GLS estimator of the expectation of the distribution of the parameters.

Finally, we choose between the continuous and discrete adjustment on the basis of the robustness of the estimations. The discrete adjustment is a priori closer to the reality at a micro level, as confirmed by the examples of the employment adjustment profiles reproduced in figures 4 and by previous studies (e.g. Suruga, 1998). Nevertheless, we opt for the continuous specification because of problems of identification of the coefficients in the different regimes. It can indeed be seen that there are only a few firms in each regime in the case of switching model specification. A way to ease this constraining assumption will be to use extensions of the variant 3 exposed above (\$3-1).

\footnotetext{
${ }^{20}$ According to several studies (e.g. Suruga, 1998), this value is around 0,3 in Japan (with a continuous specification and annual data).

${ }^{21}$ These results are not reproduced here and can be requested from the authors, as all the estimations.
} 


\subsection{A lower speed of adjustment in the 1990s than in the 1970s despite an acceleration at the end of the period (H1).}

To test the hypothesis H1, we successively resort to two complementary methods, which allow us to check the robustness of our results ${ }^{22}$. The first method is recursive: the first estimation concerns the period 1971-1981 and the last estimation is done for 1971-2001. For each estimation period, we have reported the Within estimator of the adjustment speed and a 95\% confidence interval (figure 5a). The apparent result is a decrease of the average speed, even if a sharp increase is observed at the end of the period. This method has however two main disadvantages: first, the quality of the estimation varies for each period (more precisely the longer is the period, the better is the estimation); second, it is very conservative in giving less weight to the most recent observations.

That is why we use an alternative method, by shifting: we estimate a fixed 15 year long period in changing only the starting point. The decreasing average speed and the acceleration at the end of the period are confirmed, with a stronger evolution for this last point (figure 5b). From these two exercises we can conclude that the adjustment speed is basically lower in the 1990s by comparison with the 1970s despite an acceleration at the end of the period.

\subsection{An increasing heterogeneity in the $1990 \mathrm{~s}$ by comparison with the 1970 s but no proof of a bipolarization of the individual speeds of adjustment (H2).}

We now compare the results obtained for the 1970s and for the 1990s. More precisely, the two sub-periods we consider are respectively 1971-1980 and 1992-2001. This choice can be justified as follows. First, we exclude the Bubble period, which is exceptional especially as concerned financial variables (Nakamura, 2001). Second, both periods (1971-1980 and 19922001) correspond to a decrease in the average size as seen in figure 3 (that is a downsizing on average). Furthermore, they both include the same number of years, so that the results of the estimations have the same robustness.

Using a model without an explicit long-term target and without switch, we find a greater variance in the 1990s in the cases of the estimation firm by firm and of the one with random coefficients, as shown in table 8. From this, we can conclude that an increasing heterogeneity of the adjustment speed across the firms in the 1990s is observed, by comparison with the 1970 s.

Does this increasing heterogeneity correspond to a diversification or to a bipolarization? In the frame of the random coefficients specification, we study the deformation of the distribution of the individual estimated coefficients over time (figures 6). For this purpose, we have to determine the individual predictors, and this requires adopting a Bayesian framework (Hsiao, 1996). The results do not confirm our initial intuition. First, the Kernel Density tends to prove that the distribution is bi-modal ... in the 1970s. Second, we find a negative Skewness for the two sub-periods - which is the sign of an asymmetric distribution - but closer to 0 in the 1990s; moreover, the Kurtosis is closer to 3, which shows that the distribution of the individual speeds in the 1990s is closer to a normal one.

\footnotetext{
${ }^{22}$ The results of these exercises are presented in figure 5, as obtained through the within estimation, because it allows to graph the confidence interval. This is not the case with the GLS estimation and random coefficients. However, the results (also available from the authors) are quite similar.
} 
Next we focus on the evolution of the individual adjustment speeds. After having ordered the firms according to their speed for the two sub-periods, we show the absence of correlation between the two orderings through a Spearman test ${ }^{23}$. In other words, for a given firm, we cannot a priori deduce its relative speed in the 1990s from the observation of its speed in the 1970. Therefore, we need complementary information (see H3). This point is confirmed by a simple exercise. If we divide our sample into three groups according to the change of the speed in the 1990s by comparison (stable, increasing, decreasing speed), we find that only $22 \%$ firms have a stable speed (in defining the stability by the following criterion: the individual speed in the 1990 s is less than $20 \%$ lower or greater by comparison with the one in the 1970s), while respectively $47 \%$ and $31 \%$ experience a decrease and an increase of their speed.

To conclude, the increasing heterogeneity is confirmed (hypothesis H2a), but the hypothesis $\mathrm{H} 2 \mathrm{~b}$ (bipolarization) is rejected at this stage. We now turn to the study of the determinants of the adjustment speed and of the increasing heterogeneity.

\subsection{How to explain the different speeds of employment adjustment at the level of the firms and the increasing heterogeneity (H3)?}

Here we regress individual firms' speeds on the set of explanatory variables (NCG and CG vectors) for different periods (tables 9). For each period, we present the results for four alternative models, the last model (4) always being the best. For the whole period (19712001), we get the following results. Concerning the non financial variables, we find significant results, with the expected sign for the size (misizel), the R\&D expenses ratio (mirdrati), the export ratio (mixprod): this sign is negative for the two former and positive for the latter. As far as the average age of employees (miagemo) is concerned, its effect is significant and contributes to a higher speed. Finally, the capital ratio (miintK1) has a positive impact on the speed, which was not expected. Concerning the non financial variables, we find the good signs and significant results for the performance (miperf5), which has a negative impact, and for three among four variables characterizing the shareholding structure: the share of foreign owners (mifore11), which accelerates the speed; the share of the financial institutions (miinstfi) and the cross-sharing (microshr), which contribute to a lower speed. As far as the impact of the Main bank (mimbl) is concerned, we find a negative sign: the more effective the link with the main Bank is, the lower the adjustment speed is. Finally, results concerning the debt are ambiguous: the DER and the interest rate paid by the firm (mider and midbtpst) have a negative impact on the speed, while the debt as a percentage of the sales (midhk) induces a higher speed. Globally, the results are satisfactory (the adjusted $\mathrm{R}^{2}$ of the best model is 0.27 ) and improve, when we introduce the financial variables, as it is shown through the comparison between model 1 and the three other models. The next question is to check if these results are robust when we consider sub-periods, basically the 1970s and the 1990s.

Our main finding is that the above results are modified significantly, when we estimate sub-period by sub-period. Our interpretation is that the determinants of the adjustment speed changed over time. First of all, the most striking result for the sub-period 1971-1980 is that

\footnotetext{
${ }^{23}$ The Spearman test allows to check the link between two orderings by sub-period as in our case. We test H0: the orders are independent / H1: the orders are identical. We get: RS =0,038 (Spearman correlation coefficient). We conclude that the orders are independent.
} 
the variable Main Bank (mimbl) is no longer significant, whatever the specification we estimate: in the 1970s, the link with the Main bank is not discriminating across firms, from the point of view of employment adjustment. If we consider the non financial variables, the following findings can be highlighted. The size (misizel) and the export ratio (mixprod) are still significant with the expected signs (respectively negative and positive). It is interesting to notice that the sign of the average age of the employees (miagemo) has now become significantly negative: "lifetime employment" is not yet a problem at that time and a high average age will not accelerate the restructuring. The variables characterizing the "history" of the firms (sincel and since2) are non significant. The ratio of R\&D expenses (mirdrati), is not introduced in the 1970s because of a lack of data. Finally, concerning the capital ratio (miintK1) we find the same unexpected result as that for the whole period. We turn now to the analysis of the financial variables. We have already mentioned the interesting result concerning the Main bank. The following variables are significant with a negative sign: the performance (miperf5), the ratio of debt to the sales (midhk), the share of the financial institutions (miinstfi) and the degree of concentration of the shareholding (mishrco2). The DER (mider) now has a significant positive impact, while the ratio of foreign shareholders (mifore 11) is no longer significant. This is not surprising because this is very low in the 1970s and not discriminating across firms.

Basically, the results are less robust for the sub-period 1992-2001. Moreover, the explanatory factors are different. The changes to be highlighted are the followings. The Main bank has again a significantly negative impact (the Main bank which kept a strong link with the firms contributes to a lower adjustment speed). This important and non intuitive result is in fact a confirmation of a previous study on the link between the performance and the existence of a Main Bank (Tsuru, 2001). As far as the size (misizel) is concerned, the results are no longer significant. We have here the confirmation of previous results, according to which the size is no more a major factor of the heterogeneity of employment adjustment across firms in the 1990s (Lechevalier 2003). We have to be more precise on this point: in the models 1 and 2, where we have not introduced all the financial variables (e.g. the Main bank), the size is significant, but the introduction of more financial variables (and, among others, the Main bank) improves the results of the estimation, whereas the size becomes non significant. Concerning the non financial variables, another noticeable finding is the fact that the average age of the employees (miagemo) now accelerates significantly the adjustment speed. One possible interpretation is the increasing pressures on the lifetime employment system, in a context of the aging of the workforce in some firms and the increasing wage-related costs. Moreover the creation date (sincel) and the ratio of R\&D expenses (mirdrati) are now significant, with the good sign (respectively positive and negative). However, surprisingly the export ratio (mixprod) is no more significant. If we now turn to the analysis of financial variables, the performance (miperf5) and the DER (mider) have both a significantly negative impact. As for the shareholding structure, the share of foreign owners (miforell) has a significantly positive impact, while the cross-sharing (microshr) has an unexpected sign.

In a next step we test two models in splitting the sample into two groups of firms according to the individual speeds of adjustment (high versus low). The results, which are not reproduced here ${ }^{24}$, tend to prove that the models are different, depending on the speed. This result has to be related to the fact that, in the 1990s, the results are much less good, when we do not distinguish between at least two groups of firms, according to their speed of adjustment, and much better when we do this distinction. This is not the case in the 1970s. We

\footnotetext{
${ }^{24}$ See note 19.
} 
interpret this fact as a sign of bipolarization, which did not appear, when we focused on the only speeds of adjustment without studying the underlying model ${ }^{25}$.

Finally, among the results we just analyzed, we distinguish between those which are robust on the whole period (with the same significant sign) and those, which might be at the centre of the changes that occurred since the beginning of the 1990s. They potentially are an explanation of the increasing heterogeneity. Among the former, the performance has always a significantly negative impact on the adjustment speed. The impact of the variables characterizing the shareholding structure is also stable, even if we noticed some changes in the details, especially the share owned by foreign firms. Among the latter, the most important are the age (negative and then positive impact), the size (significantly negative and then no more significant), the Main Bank (non significant impact and then significantly negative) and, to a less extent, the debt, whose impact becomes negative after having been positive, if one considers the DER.

\section{CONCLUSION}

The present study, based on the NEEDS-FQ database, questions what has been called "the end of the Japanese style lifetime employment system", through an analysis of the employment adjustment at the level of firms during the period 1970-2001 in a panel framework.

We have obtained the two main following findings. First, the average speed of employment adjustment is lower during the current crisis than in the 1970s, while an increasing heterogeneity across firms is observed in the 1990s. This heterogeneity is not a bipolarization of the individual speeds of adjustment, but rather a bipolarization of the underlying characteristics of the employment model. Thus, we have here, in the case of Japan, a confirmation of what Katz and Darbishire (2000) found for other countries, using another methodology than ours. However, the kind of bipolarization we found could be specific to Japan.

This last remark is related to our second main finding. The financial structure of the firms seems to play a major role in this trend of increasing heterogeneity. More precisely, we found it is necessary to take into account both non financial and financial variables to explain the path of the employment adjustment at the level of the firms. But the most determining factors differ in the 1970s and in the 1990s, except for the performance (which always contributes to a lower speed) and for most of the variables characterizing the shareholding structure. Indeed, as for the financial factors, the impact of the Main Bank become significant (and negative) in the 1990 whereas it was not significant in the 1970s; the DER turns from significantly positive in the 1970 s to significantly negative in the 1990s; the percentage of share owned by foreign firms becomes significantly positive in the 1990s. As for the non financial factors, the most striking results concern the size and the export ratio, which had a significant impact in the 1970s (respectively negative and positive), but no more in the 1990s. Besides, the impact of the average age of the employees, from negative, becomes positive.

\footnotetext{
${ }^{25}$ To a certain extent, this point is more important than the discussion about the discrete versus continuous form of the adjustment, as it can be inferred by Hildreth and Ohtake (1998): this form depend fundamentally of the level of aggregation.
} 
Finally, our model is less robust in the 1990s if it is estimated for all the firms, whereas it is quite better (both in absolute and by comparison with the results obtained for the 1970s) if we split the sample into at least two groups according to their speed. This is indeed interpreted as a sign of bipolarization of the employment adjustment process in the 1990s.

From a technical point of view, it is important to note that the quality and the hoped originality of these results mainly come from the adoption of a panel framework and above all from the choice of the estimation method. Indeed, this method produced individual coefficients as for a firm by firm estimation, improved by correcting abnormal values using all the information. It allowed analysing rigorously the deformation of these coefficients' distribution and of the determinants of the individual speeds. Another point to be underlined is the confirmation that the speed is only one aspect of the adjustment model and it is necessary to consider the underlying structure to get a better understanding. In our view, this point is at least as much important as the discussion on the discrete / continuous nature of the adjustment process, for which we did not propose any improvement.

It is now possible to turn back to the general issues at stake, as pointed out in the beginning of this paper. As we have already mentioned, the present study questions the interpretation of the current evolution on the labour market in term of the end of the Japanese style lifetime employment system, and contributes to solve the micro - macro paradox. This is precisely the message of the findings concerning the stability of the average speed of adjustment and the increasing heterogeneity across firms. Besides, we have to be more specific about this last point. This is not the result of a statistical artefact, due to the resort of the micro data, as shown by the comparison between the 1970s and the 1990s. This heterogeneity takes the form of a bipolarization between the firms, whose underlying model of adjustment remains approximately stable and those, whose model changes toward a more financial logic of the adjustment, and sometimes a higher speed. By controlling the sector and finding a less important role of the size, we indeed highlighted that the factors of the increasing heterogeneity are mainly financial. This is a confirmation that the financial dynamics since the 1980s had a strong impact on the whole system and that the current crisis does not only reveal a pre-existing heterogeneity. Among these financial factors, we found that the Main bank plays a discriminating role in the 1990s and contributes to lower speed. This result is one more piece in the debate on the effective role of the Main bank in the Japanese-style corporate governance and employment system. However, our study also pointed out that we cannot limit the analysis to the financial dynamics and that some employment practices are increasingly raising problem, as it can be stated from the analysis of the positive correlation between the average age of employees and the speed of adjustment in the 1990s. Moreover, our result concerning the impact of financial factors has to be confirmed and specified by future studies.

Finally, the limits of this empirical work are as many routes for further research. This study is first limited by an important survival bias, because we focused on firms in activity between 1970 and 2001. This is all the more a problem that the 1990s are characterized by an increasing number of bankruptcies, which have an important impact on employment security. This bias in fact probably leads to an underestimation of the firms' actual heterogeneity. In addition, we took into account only one aspect of the firms' employment policies, i.e. the management of regular employees, and, due to lack of data, were not able to analyze practices related to non-regular workers -- which are also probably another source of heterogeneity. 


\section{References.}

ABE Masahiro (2002), Corporate Governance Structure and Employment Adjustment in Japan: An Emprirical Analysis Using Corporate Finance Data, Industrial Relations, 41 - 4.

ABRAHAM Katharine G. \& HOUSEMAN Susan N. (1989), Job Security and Workforce Adjustment: How Different Are US and Japanese Practices, Journal of the Japanese and International Economies, 3, pp 500-521.

AOKI Masahiko (1990), Toward an Economic Model of the Japanese Firm, Journal of Economic Literature (28), March.

BOYER Robert \& JUILLARD Michel (1998), The Contemporary Japanese Crisis and the Transformations of the Wage Labor Nexus, Document de travail du CEPREMAP.

BOYER Robert \& YAMADA Toshio edit. (2000), Japanese Capitalism in Crisis. A regulationist interpretation, Routledge.

CAHUC Pierre \& ZYLBERBERG André (2001), Le marché du travail, De Boeck Université. CHUMA Hiroyuki (2002), Employment Adjustments in Japanese Firms during the Current Crisis, Industrial Relations, 41 - 4.

DORE Ronald \& TAIRA Koji (1986), Structural adjustment in Japan (1970-1982), ILO.

DORMONT Brigitte (1996), Seeking for Labor Demand Heterogeneity, Annales d'Economie et de Statistique, $\mathrm{n}^{\circ} 41 / 42$.

EISNER R. \& STROTZ R. (1963), Determinants of Business Investment, in Impact of Monetary Policy, part I, Commission on Money and Credit, Englewood Cliffs.

FAVEREAU (1991), Irréversibilités et institutions : problèmes micro-macro, in BOYER Robert, CHAVANCE Bernard \& GODARD Olivier (dir.), Les figures de l'irréversibilité en économie, Editions de l'EHESS.

GARVEY G.T. \& SWAN P. L. (1992), The interaction between financial and employment contracts. A formal Model of Japanese corporate governance, Journal of the Japanese and International Economies, 6.

HAMERMESH Daniel S. (1989), Labor Demand and the Structure of Adjustment Costs, The American Economic Review, vol. 79, ${ }^{\circ} 4$.

HAMERMESH Daniel S. (1993), Labor Demand, Princeton University Press.

HAMERMESH Daniel S. \& PFANN G. (1993), Adjustment Costs in Factor Demand, Journal of Economic Literature, Vol. 34, pp 1264-1292.

HASHIMOTO Masanori (1993), Aspects of Labor Market Adjustments in Japan, Journal of Labor Economics, vol. 11, No 1.

HILDRETH K. G. Andrew \& OHTAKE Fumio (1998), Labor Demand and the Structure of Adjustment Costs in Japan, The Journal of the Japanese and International Economies 12, 131150.

HORIUCHI Akiyoshi (1995), Financial Structure and Managerial Discretion in the Japanese Firm: An Implication of the Surge of Equity-related Bonds in Okabe Mitsuaki, The structure of the Japanese Economy.

HOSHI Takeo \& KASHYAP Anil K. (2001), Corporate Financing and Governance in Japan. The Road to the Future, the MIT Press.

HSIAO Cheng (1996), Random Coefficient Models, in MATYAS Laszlo \& SEVESTRE Patrick (dir.) The Econometrics of Panel Data: A Handbook of the Theory with Applications, Second edition. Advanced Studies in Theoretical and Applied Econometrics, vol. 33. Dordrecht; Boston and London: Kluwer Academic, pp. 77-99.

HSIAO Cheng (1989), Modelling Ontario Regional Electricity System Demand Using a Mixed Fixed and Random Coefficient Approach, Regional Science and Urban Economics, 19, 565-587. 
JUDSON R.A. \& OWEN A.L. (1999), Estimating Dynamic Panel Data Models: a Guide for Macroeconomists, Economic Letters, vol. 65, pp 9-15.

KANEKO Masaru (2001), Aoki's theory and the reality of the Japanese firms, in KAMII Yoshihiko \& NOMURA Masami (dir.), Japanese firms - theory and reality, Minerva shobo (in Japanese).

KANEKO Masaru 金子勝 (2000) Kyasshu-furô keiei koso kyôki da キャッシュフロー経営 こそ狂気だ (C'est le 《cash-flow management » qui est de la folie), Bungei shunjû 文藝春秋, novembre (in Japanese).

KATZ, H. C. \& DARBISHIRE O. (2000), Converging Divergencies, Ithaca, NY: Cornell University Press.

KIM Dong-One, YU Gyu-Chang \& PARK Woo-Sung (2002), Changing Patterns of Korean Human Resource Management Systems Since the Financial Crisis: An Analysis of 1998-2000 Panel Data, Proceedings of the 32nd Meetings of the Japan Society of Human Resource Management, pp. 25-38, Ishimaki Senshu University, Japan, June 22-23.

LAZONICK William (1998), The Japanese Financial Crisis, Corporate Governance, and Sustainable Prosperity, INSEAD, Working Paper No. 227.

LECHEVALIER Sébastien (2003), La resegmentation contemporaine du marché du travail japonais en perspective historique, Cipango $\mathrm{n}^{\circ} 11$.

LECHEVALIER Sébastien (2002), Japon. Les restructurations dans l'électronique : vers le downsizing à l'américaine?, Chroniques internationales de l'IRES nº74, janvier.

LECHEVALIER Sébastien (2001), Japon. La sécurité de l'emploi au cour du compromis salarial émergent, Chroniques internationales de l'IRES n ${ }^{\circ} 68$, janvier.

MINISTRY OF LABOUR (2001, 1999, 1998), White paper on Labour.

MIWA Yoshiro (1996), Firms and Industrial Organization in Japan, MacMillan Press.

NAKAMURA Junichi (2001), Empirical Reassessment of Japanese Corporate Investment Behavior: Features and Changes Since the 1980's, Based on Micro level Data, Research Report of the Development Bank of Japan $n^{\circ} 12$, March.

NICKELL S. (1981), Biases in Dynamic Models with Fixed Effects, Econometrica, vol. 49, pp 1399-1416.

OI W. Y. (1962), Labor As a Quasi-fixed Factor, The Journal Of Political Economy, LXX-6.

OKAZAKI Tetsuji (1995), Employment adjustment and firms adaptability in Corporate Behavior Study group, The adaptability of Japanese firms, Nihon Keizai Shimbun [en japonais].

SAKO Mari \& SATO Hiroki (1997), Japanese Labour and Management in Transition, Routledge.

SURUGA Terukazu (1998), Employment Adjustment in Japanese Firms: Negative Profits and Dismissals, in OHASHI Isao \& TACHIBANAKI Toshiaki dir., Internal Labour Markets, Incentives and Employment, Macmillan Press.

SWAMY P.A.(1970), Efficient Inference in a Random Coefficient Regression Model, Econometrica, 38, 311-323.

TACHIBANAKI Toshiaki \& TAKI Atsuhiro (2000), Capital and Labour in Japan. The Functions of Two Factors Markets, Routledge.

TSURU Kotaro (2001), Bank Relationship and Firm Performance: Evidence from Selected Japanese firms in the Electrical Machinery Sector, RIETI discussion paper. 


\section{Appendix.}

\section{Appendix 1: Dynamics of employment when the costs of adjustment are quadratic.}

We consider the standard program of a firm which maximises an expected steam of discounted cash flows. We denote $E_{t}$ the conditional expectation given the information at time $t$. In order to simplify the calculus, we consider a quadratic production function (Cahuc \& Zylberberg 2001), $F\left(X_{t}, L_{t}\right)=X_{t} L_{t}-(b / 2) L_{t}^{2}, b>0$ where $X_{t}$ denotes a combination of exogenous inputs. The expected profits are defined as:

$$
\Pi_{t}=E_{t} \sum_{i=0}^{\infty}\left(\frac{1}{1+r}\right)^{t}\left[F\left(X_{t+i}, L_{t+i}\right)-w_{t+i} L_{t+i}-C\left(L_{t+i}-L_{t+i-1}\right)\right]
$$

In equilibrium, we get:

$$
c E_{t} L_{t+1}-[c+(1+r)(c+b)] L_{t}+c(1+r) L_{t-1}+(1+r)\left(X_{t}-w_{t}\right)=0
$$

or:

$$
\left[\frac{c}{c+(1+r)(c+b)}\right] E_{t} L_{t+1}-L_{t}+\left[\frac{c(1+r)}{c+(1+r)(c+b)}\right] L_{t-1}+\left[\frac{(1+r)}{c+(1+r)(c+b)}\right]\left(X_{t}-w_{t}\right)=0
$$

Let us introduce $a_{0}$ and $a_{1}$ as:

$$
a_{0}=\left[\frac{c}{c+(1+r)(c+b)}\right] \quad a_{1}=a_{0}(1+r)
$$

The equation (1) can be solved by the method of undetermined coefficients. For that we assume that there exists a solution and we guess the following functional form:

$$
L_{t}=\lambda L_{t-1}+\sum_{i=0}^{\infty} \gamma_{i} E_{t}\left(X_{t+i}-w_{t+i}\right)
$$

By identifying the terms in the equation (2) of $L_{t}$ and in the equation (1) with the expression of $E_{t} L_{t+1}$ derived from (2), we show that (Cahuc \& Zylberberg 2001) the parameters $\lambda$ and $\gamma_{i}$ verify the conditions:

$$
\lambda=\frac{a_{1}}{1-\lambda a_{0}} \quad \gamma_{0}=\left(\frac{1}{1-\lambda a_{0}}\right) \frac{a_{1}}{c} \quad \gamma_{i}=\left(\frac{a_{0} a_{1}}{c} \gamma_{0}\right)^{i} \gamma_{0} \quad \forall i \geq 1
$$

If we consider the stable root of the second order equation defined in $\lambda$, then we get the following expression of the autoregressive parameter:

$$
\lambda=\frac{1-\sqrt{1-4(1+r) a_{0}^{2}}}{2 a_{0}}=\frac{c+(1+r)(b+c)}{2 c}-\frac{1}{2 c}\left\{[c+(1+r)(b+c)]^{2}-(1+r) c^{2}\right\}^{\frac{1}{2}}
$$


Figure 1: Evolution of the speed of employment adjustment to the production between the 1970s and the 1990s (stylized fact 1).

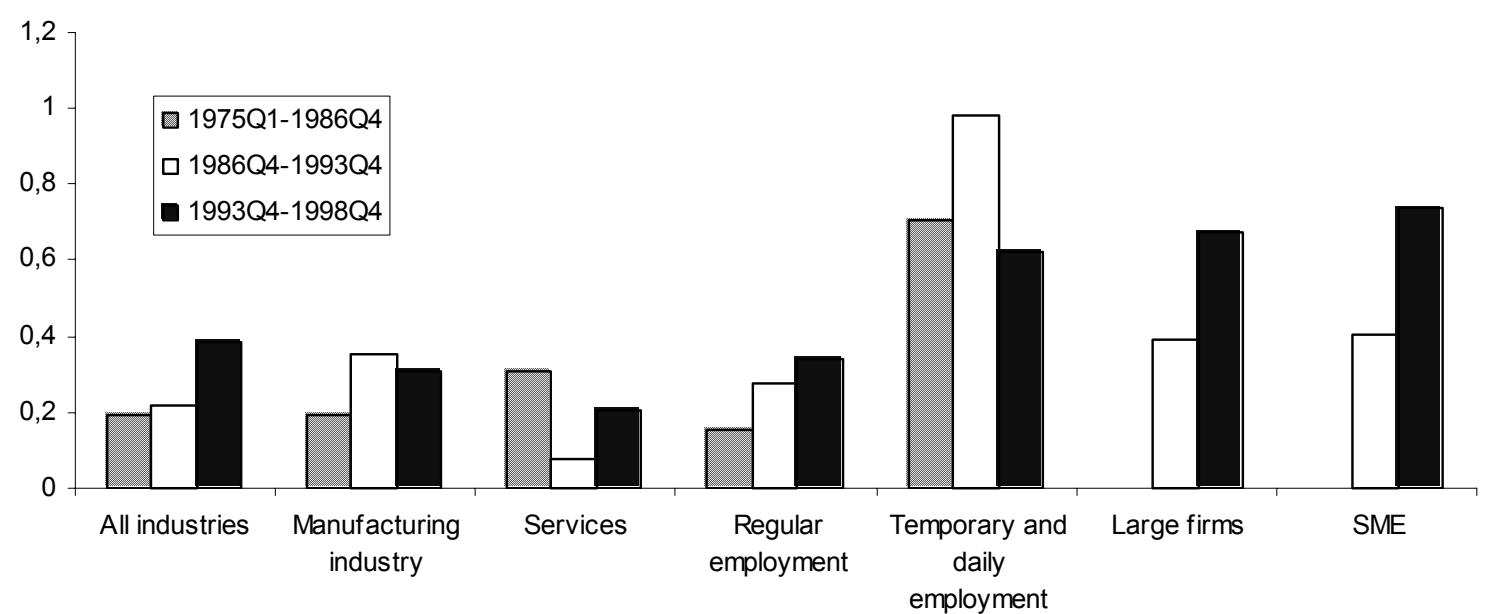

Source: Ministry of Labour, Monthly labour Force Survey.

Note: The data are quarterly and for firms with more than 30 employees.

This result is based on the estimation of the following labor demand equation:

$\ln L=a+b \ln X+c \ln (W / R)+d \ln L_{-1}$

where $\mathrm{L}$ : number of employees; $\mathrm{X}$ : production (real sales) $; \mathrm{W}$ : average real wage ; $\mathrm{R}$ : deflator ; $1-\mathrm{d}$ is the speed of adjustment, which is represented on the figure. For example, in the case of the manufacturing industry between 1993Q4 and 1998Q4, we obtained $1-d=0,386$ on a quarterly data basis, that is 0,858 on an annual basis $(85,8 \%$ of the optimal speed).

Figure 2: Impact of losses on the speed of adjustment (stylized fact 2).

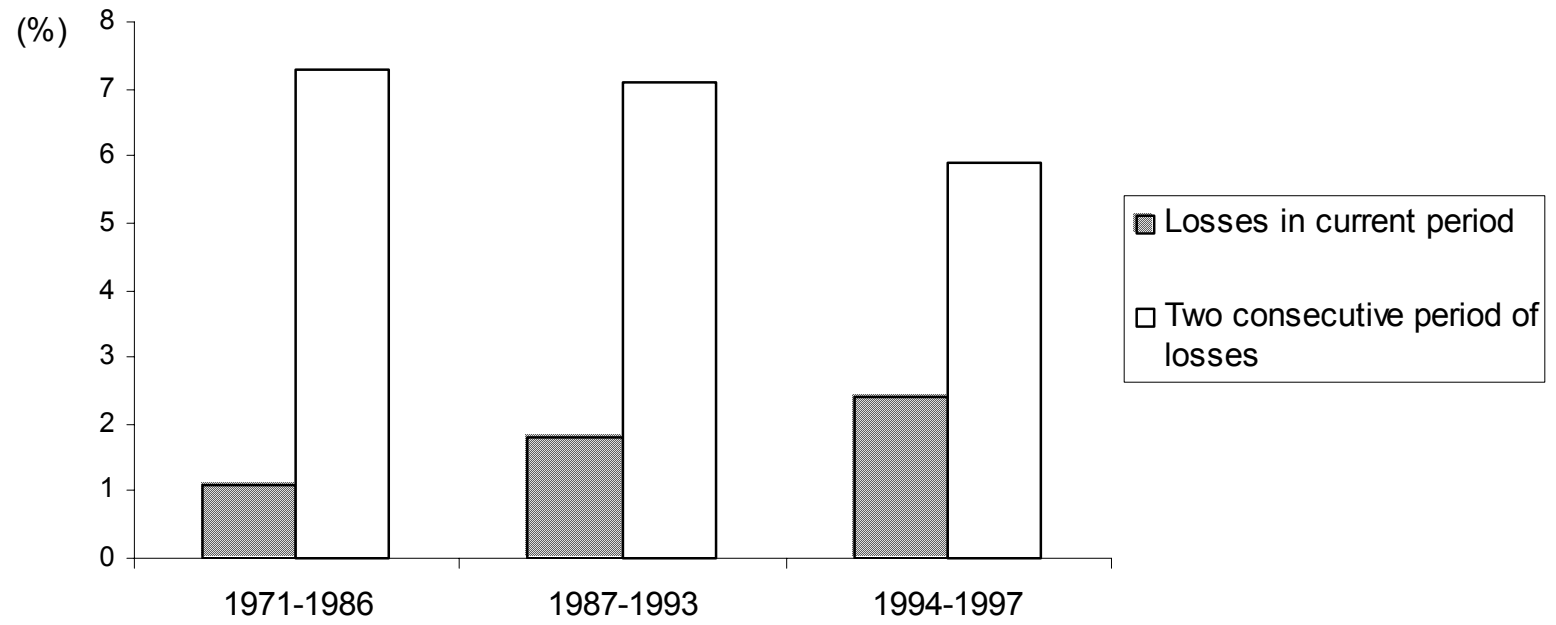

Source: DBJ (Development Bank of Japan) database.

The sample is composed of 1190 firms, including 112 from the electrical machinery sector (firms listed at the Tokyo, Osaka and Nagoya Stock Exchanges from 1971 to 1997).

Note: This result is based on the estimation of the following labor demand equation:

$L=a+b X+c W+d D_{1}+e D_{2}$

where L: variation of the number of employees as a $\%$ of the level of the preceding year; $\mathrm{X}$ : variation of the real sales as a $\%$ of the level of the preceding year; $\mathrm{W}$ : variation of the real wage as a $\%$ of the level of the preceding year; $\mathrm{D}_{1}$ : dummy for losses in current period; $\mathrm{D}_{2}$ : dummy for two consecutive years of ordinary losses. 
Table 1: List of the 126 firms of the panel.

\begin{tabular}{|c|c|c|c|c|c|}
\hline 1 & IBIDEN & 2 & MINEBEA & 3 & HITACHI \\
\hline 4 & TOSHIBA & 5 & MITSUBISHI ELECTRIC & 6 & FUJI ELECTRIC \\
\hline 7 & TOYO ELECTRIC MFG. & 8 & YASKAWA ELECTRIC & 9 & SHINKO ELECTRIC \\
\hline 10 & MEIDENSHA & 11 & ORIGIN ELECTRIC & 12 & SANYO DENKI \\
\hline 13 & DENYO & 14 & HITACHI KOKI & 15 & SANOH INDUSTRIAL \\
\hline 16 & JAPAN SERVO & 17 & MAKITA & 18 & MATSUSHITA SEIKO \\
\hline 19 & TOSHIBA TEC & 20 & SHIBAURA MECHATRONICS & 21 & TAKAOKA ELECTRIC MFG. \\
\hline 22 & DAIHEN & 23 & NISSIN ELECTRIC & 24 & TOGAMI ELECTRIC MFG. \\
\hline 25 & OSAKI ELECTRIC & 26 & OMRON & 27 & MORIO DENKI \\
\hline 28 & NITTO ELECTRIC WORKS & 29 & NEC & 30 & FUJITSU \\
\hline 31 & OKI ELECTRIC INDUSTRY & 32 & IWATSU ELECTRIC & 33 & NEC INFRONTIA \\
\hline 34 & DENKI KOGYO & 35 & SANKEN ELECTRIC & 36 & TOYO COMMUNICATION EQUIPMENT \\
\hline 37 & MEISEI ELECTRIC & 38 & TAIKO ELECTRIC WORKS & 39 & TAMURA ELECTRIC WORKS \\
\hline 40 & NIPPON SIGNAL & 41 & KYOSAN ELECTRIC MFG. & 42 & DAIDO SIGNAL \\
\hline 43 & NOHMI BOSAI & 44 & $\mathrm{HOCHIKI}$ & 45 & JAPAN RADIO \\
\hline 46 & MATSUSHITA ELECTRIC INDUSTRIAL & 47 & SHARP & 48 & ANRITSU \\
\hline 49 & FUJITSU GENERAL & 50 & HITACHI KOKUSAI ELECTRIC & 51 & SONY \\
\hline 52 & TOKIN & 53 & AIWA & 54 & TDK \\
\hline 55 & TEIKOKU TSUSHIN KOGYO & 56 & SANYO ELECTRIC & 57 & KENWOOD \\
\hline 58 & MITSUMI ELECTRIC & 59 & TAMURA & 60 & ALPS ELECTRIC \\
\hline 61 & IKEGAMI TSUSHINKI & 62 & TOKYO COSMOS ELECTRIC & 63 & PIONEER \\
\hline 64 & TOWA MECCS & 65 & TENSHO ELECTRIC INDUSTRIES & 66 & MATSUSHITA COMMUNICATION IND. \\
\hline 67 & KYUSHU MATSUSHITA ELECTRIC & 68 & NIPPON COLUMBIA & 69 & VICTOR COMPANY OF JAPAN \\
\hline 70 & SANSUI ELECTRIC & 71 & FOSTER ELECTRIC & 72 & CLARION \\
\hline 73 & SMK & 74 & YOKOWO & 75 & TOKO \\
\hline 76 & TEAC & 77 & HOSIDEN & 78 & HITACHI MAXELL \\
\hline 79 & YOKOGAWA ELECTRIC & 80 & SHINDENGEN ELECTRIC MFG. & 81 & YAMATAKE \\
\hline 82 & ANDO ELECTRIC & 83 & DKK.TOA & 84 & NIHON KOHDEN \\
\hline 85 & CHINO & 86 & KYOWA ELECTRONIC INSTRUMENTS & 87 & ONO SOKKI \\
\hline 88 & TABAI ESPEC & 89 & SAWAFUJI ELECTRIC & 90 & DENSO \\
\hline 91 & TOKO ELECTRIC & 92 & STANLEY ELECTRIC & 93 & IWASAKI ELECTRIC \\
\hline $94 \mid$ & USHIO & 95 & OKAYA ELECTRIC INDUSTRIES & 96 & JAPAN STORAGE BATTERY \\
\hline 97 & YUASA & 98 & SHIN-KOBE ELECTRIC MACHINERY & 99 & TOYO TAKASAGO DRY BATTERY \\
\hline 100 & FURUKAWA BATTERY & 101 & JEOL & 102 & CASIO COMPUTER \\
\hline 103 & FDK & 104 & ENPLAS & 105 & KYOCERA \\
\hline 106 & ELNA & 107 & NIHON INTER ELECTRONICS & 108 & SUMITOMO SPECIAL METALS \\
\hline 109 & TAIYO YUDEN & 110 & JAPAN RESISTOR MFG. & 111 & MURATA MFG. \\
\hline 112 & LEAD & 113 & NITTO DENKO & 114 & HOKURIKU ELECTRIC INDUSTRY \\
\hline 115 & MATSUSHITA ELECTRIC WORKS & 116 & KOKUSAN DENKI & 117 & MORI DENKI MFG. \\
\hline 118 & SHIZUKI ELECTRIC & 119 & TOKAI RIKA & 120 & $\mathrm{NICHICON}$ \\
\hline $121 \mid$ & NIPPON CHEMI-CON & 122 & NIPPON TUNGSTEN & 123 & KOA \\
\hline 124 & DAINIPPON SCREEN MFG. & 125 & CANON & 126 & MUTOH INDUSTRIES \\
\hline
\end{tabular}

Source: NEEDS-FQ. 
Table 2: Construction of the variables CG and NCG.

$\mathbf{C G}=$ (ROA, perfo4, perfo5, debtpast, DER, DHK, sharecon, sharemoy, crosshar, instifi, invifi, Fore1, Fore2, market, indicMB1, MB1, MB2, rgMB2).

NCG = (ssecteur, size1, size2, since1, since2, Xprod, expdownsiz, expnegprof, ratioRD, intK1, intK2, land, agemoy, dr).

Table 2a: CG (Corporate governance) Vector.

\begin{tabular}{|c|c|c|c|c|}
\hline Category & variable & Source & definition & $\begin{array}{l}\text { Expected } \\
\text { impact on the } \\
\text { speed of } \\
\text { employment } \\
\text { adjustment }\end{array}$ \\
\hline \multirow[t]{3}{*}{ 1) Performance } & ROA & NEEDS & $\begin{array}{l}\text { (operating profit }+ \text { interest and dividend } \\
\text { received) / (total assets) en } \%\end{array}$ & - \\
\hline & Perfo4 & NEEDS & Current profit/total capital (\%) & - \\
\hline & Perfo5 & NEEDS & Ordinary profit/sales $(\%)$ & - \\
\hline \multirow[t]{3}{*}{ 2) Debt } & Debpast & NEEDS & $\begin{array}{l}\text { Interest expense \& Discount premium / total } \\
\text { fixed liability en } \%\end{array}$ & + \\
\hline & DER & NEEDS & $\begin{array}{l}\text { total fixed liabilities/(total capital }+ \text { total } \\
\text { reserve) en } \%\end{array}$ & + \\
\hline & DHK & NEEDS & $\begin{array}{l}\text { Total debt as a percentage of sales (Hoshi \& } \\
\text { Kashyap (2001)) : } 100 *(\text { total fixed liability } \\
+ \text { total current liability) / sales and operating } \\
\text { revenues }\end{array}$ & + \\
\hline \multirow[t]{7}{*}{$\begin{array}{l}\text { 3) Shareholding } \\
\text { Structure }\end{array}$} & sharecon & NEEDS & $\begin{array}{l}\% \text { of shares owned by the } 10 \text { principal } \\
\text { shareholders }\end{array}$ & + \\
\hline & sharemoy & NEEDS & $\begin{array}{l}\text { Average number of shares owned by the } \\
\text { shareholders }\end{array}$ & Non significant \\
\hline & crosshar & NEEDS & $\%$ of shares owned by other firms & - \\
\hline & Instifi & & $\%$ of shares owned by financial institutions & - \\
\hline & indivfi & & $\begin{array}{l}\% \text { of shares owned by individual } \\
\text { shareholders }\end{array}$ & Non significant \\
\hline & Fore1 & NEEDS & $\%$ of shares owned by foreign firms & + \\
\hline & Fore2 & $\mathrm{JCH}$ & $\%$ of shares owned by foreign firms & + \\
\hline Listing market & Market & $\mathrm{JCH}$ & $\begin{array}{l}\text { Dummy taking the value } 1 \text { or } 2 \text { according } \\
\text { the listing market and } 0 \text { if not listed }\end{array}$ & $?$ \\
\hline \multirow[t]{4}{*}{ 4) Main bank } & indicMB1 & KNK & $\begin{array}{l}\text { Dummy taking the value } 1 \text { if the firm has a } \\
\text { identified Main Bank and } 0 \text { if not }\end{array}$ & $?$ \\
\hline & MB1 & KNK & $\begin{array}{l}\text { Ratio of the bank debt owned by the Main } \\
\text { bank }(\%)\end{array}$ & - \\
\hline & MB2 & $\mathrm{JCH}$ & $\%$ of shares owned by the Main Bank & - \\
\hline & $\operatorname{rgMB} 2$ & $\mathrm{JCH}$ & $\begin{array}{l}\text { Rank of the Main Bank among the main } \\
\text { shareholders }\end{array}$ & - \\
\hline
\end{tabular}


Table 2b: NCG (Non Corporate governance)Vector.

\begin{tabular}{|c|c|c|c|c|}
\hline Category & variable & Source & definition & $\begin{array}{l}\text { Expected } \\
\text { impact on the } \\
\text { speed of } \\
\text { employment } \\
\text { adjustment }\end{array}$ \\
\hline Activities & Ssecteur & $\mathrm{JCH}$ & $\begin{array}{l}\text { Dummy taking the values } 1 \text { to } 7 \\
\text { according to the main activity of the } \\
\text { firm }\end{array}$ & $?$ \\
\hline \multirow[t]{2}{*}{ Size } & Size1 & NEEDS & Number of employees & - \\
\hline & Size2 & NEEDS & Total assets & - \\
\hline \multirow[t]{4}{*}{ History } & Since1 & $\mathrm{JCH}$ & Creation date of the firm & + \\
\hline & Since2 & $\mathrm{JCH}$ & Date of the first listing & + \\
\hline & Expdownsiz & NEEDS & $\begin{array}{l}\text { Cumulative variable : one adds } 1 \text { every } \\
\text { year when the employment decrease of } \\
\text { more than } 10 \% ; 0 \text { if not }\end{array}$ & $?$ \\
\hline & expnegprof & NEEDS & $\begin{array}{l}\text { Cumulative variable : one adds } 1 \text { every } \\
\text { year in case of loss; } 0 \text { if not }\end{array}$ & $?$ \\
\hline Export ratio & Xprod & $\mathrm{JCH}$ & Exports as a \% of total sales & + \\
\hline $\begin{array}{l}\text { Ratio of } \mathrm{R} \& \mathrm{D} \\
\text { expenses }\end{array}$ & RDratio & NEEDS & $100 *$ R\&D expenses / sales & - \\
\hline \multirow[t]{2}{*}{ Capital ratio } & intensK1 & NEEDS & $\begin{array}{l}100^{*} \text { (Tangible fixed assets total }+ \\
\text { Intangible Fixed Asset total) / number } \\
\text { of employees }\end{array}$ & - \\
\hline & intensK2 & NEEDS & $\begin{array}{l}100^{*} \text { Tangible fixed assets total / } \\
\text { number of employees }\end{array}$ & - \\
\hline $\begin{array}{l}\text { Average age of } \\
\text { employees }\end{array}$ & Agemoy & $\mathrm{JCH}$ & Average age of employees & - \\
\hline Union & $\mathrm{dr}$ & $\begin{array}{l}\text { Denki } \\
\text { rengo }\end{array}$ & $\begin{array}{l}\text { Dummy taking the value } 1 \text { if the firm is } \\
\text { affiliated to denki rengo; } 0 \text { if not }\end{array}$ & $?$ \\
\hline
\end{tabular}

Notes :

1) For the variables build from JCH and KNK, we considered only 4 years:1977, 1987, $1991,1999$. Consequently these variables are not continuous. Basically, it does not raise any problem for variables like the one related to the relation with the main bank, which are very stable. However, the situation is not the same for Xprod whose year to year variation is sensitive and has a seasonally component. Anyway, we just consider the spring issue of the JCH.

2) Supplementary remarks for certain variables.

indicMB1: Generally speaking, many problems are associated to the construction of the variable characterizing the Main Bank. Thanks to the dummy indicMB1 we are able to distinguish among different situations, depending on available data, but also on the existence of a main bank for a given firm. More precisely, indicMB1 takes the value

- 1 if there is no "problem", that is when all the data are available and when the Main Bank is the same during the whole period (79 firms);

- 11 when only one year is missing (4 firms);

- 2 when the main bank is not the same during the whole period ( 8 firms);

- 0 when there is an identification "problem" (35 firms). This problem may come from the data or from the nature of the main lender. For examples, in 1987, the entire debt of Toshiba Tec (code 19) is hold by the firm pension association (Nenkin jigyo dan), by an investment fund for the technology in the case of Nitto Denko (code 113). Consequently, these two firms have no Main Bank in the sense of our definition. In these two cases, the dummy indicMB1 allows us to take into account the idea, according to which it is wrong to suppose that all the Japanese firms have a Main Bank, with which the intensity of the link would be variable, according to the ratio of debt hold by the main bank ${ }^{26}$.

MB2: It is important to note that the percentage of the shares of a given firm owned by a bank is legally limited to $5 \%$.

\footnotetext{
${ }^{26}$ See MIWA Yoshiro (1996).
} 
Ssecteur: This variable is a dummy we introduced to take into account the diversity of the activities whithin the electrical machinery sector. As a proxy, we refer to the categorization realized by Nikkei. The dummy respectively takes the values $1,2,3$, etc. according to the sub-sector into which is classified the main activity of a given firm. For this purpose, we extract the information from the Japan Company Handbook. It is noticeable that not only the main activity of the firms has changed during the studies period but also the categories themselves changed over time:

ssecteur 1977: 1 = chemistry; 2 = electronic parts; $3=$ heavy electronics; $4=$ non heavy eletronics; $5=$ electronics; $6=$ optical; 7 = others;

ssecteur 1987: 1 = chemistry ; 2 = machinery parts ; 3 = heavy electrical machinery ; $4=$ communication equipment; $5=$ consumers electronics (parts); $6=$ measurement equipments; $7=$ other electrical machinery; 8 : precision instrument; 9 : other manufacturing.

ssecteur 1991: $1=$ chemistry ; $2=$ machinery parts ; $3=$ heavy electrical machinery ; $4=$ communication equipment; $5=$ consumers electronics (parts); $6=$ measurement equipments; $7=$ other electrical machinery; 8 : precision instrument; 9 : other manufacturing. ssecteur 1999: 1 = chemistry; 2 = electric machinery; 3 = transport machinery; 4 = machinery.

3) In this article, all the explanatory variables have not been tested. This is mainly due to technical difficulties, especially the discrete nature of some variables: indicMB1, rgmb2, Ssecteur, Market, Expdownsiz, expnegprof, $d r$.

4) We made a cross-section estimation, by calculating the means by sub-period. To distinguish from the initial variables, we add the prefix "mi" in the presentation of the results ("for mean by i").

5) We modified some variables, for which we have only few observations (when the sources are JCH et KNK). Depending on the considered sub-periods (1971-1980) and (1992-2001), we add respectively the observations for the years 1987 and 1991, to the observations for the "1970s" (1977) and for the "1990s" (1999). It leads to the construction of the variables: mifore $1, \operatorname{mimb11,\operatorname {mimb}21,\operatorname {mixprod}1.}$

5) In taking into account the shape of the evolution of some financial variables, we restricted the reference period for which we calculated the mean. It allows us to eliminate abnormal values and outliers. Thus, mishrco2 is built for $\mathrm{tt}>1974$ and mifore11 for $\mathrm{tt}>1972$.

6) In the last column of tables $2 a$ and $2 b$ we indicate the expected sign of the coefficient. This is sometimes difficult to determine a priori because it depends on the general context. For example, the average age of the employees can have a positive or a negative impact on the speed, depending on the employment policy of the firm (see $§ 1-2$ ).

Table 3: Basic features of the variables.

\begin{tabular}{|c|c|c|c|c|c|c|c|c|}
\hline \multirow{2}{*}{\begin{tabular}{|l|} 
Variables \\
Via
\end{tabular}} & \multicolumn{2}{|c|}{$1971-2001$} & \multicolumn{2}{|c|}{$1971-1980$} & \multicolumn{2}{|c|}{ 1981-1991 } & \multicolumn{2}{|c|}{$1992-2001$} \\
\hline & Mean & Itandard Deviatio & Mean & Btandard Deviatio & Mean & Ftandard Deviation & Mean & Standard Deviation \\
\hline Regular employees & 5318 & 11899 & 4810 & 11466 & 5504 & 12152 & 5671 & 12076 \\
\hline Real average payment & 4,742 & 3,049 & 1,891 & 0,686 & 4,306 & 1,279 & 8,359 & 2,280 \\
\hline Average Age of employees & 35,2 & 4,0 & 31,5 & 2,9 & 35,3 & 3,4 & 38,6 & 2,8 \\
\hline Real average sales & 195636,5 & 586830,8 & 55572,0 & 146986,1 & 181686,9 & 465653,1 & 365051,9 & 888679,3 \\
\hline Real Average productivity & 30,4 & 26,9 & 10,8 & 7,1 & 27,7 & 13,1 & 55,1 & 32,1 \\
\hline Average operating profit & 8168,062 & 23361,270 & 5428,383 & 14658,180 & 11427,840 & 28508,180 & 7595,950 & 24426,290 \\
\hline Average ROA & 6,713 & 5,450 & 9,670 & 5,374 & 7,152 & 4,915 & 3,083 & 3,753 \\
\hline Average perfo4 & 0,542 & 307,567 & 8,654 & 83,345 & 0,905 & 96,199 & $-8,794$ & 534,039 \\
\hline Average perfo5 & 4,285 & 9,642 & 5,407 & 5,559 & 5,309 & 5,045 & 1,925 & 15,083 \\
\hline Average Debtpast & 20,142 & 135,803 & 26,383 & 20,129 & 19,409 & 46,484 & 14,123 & 236,768 \\
\hline Average DER & 48,981 & 163,072 & 49,540 & 253,054 & 44,237 & 46,569 & 53,591 & 111,106 \\
\hline $\begin{array}{l}\text { Average dhk } \\
\text { Average } \% \text { of shares owned by }\end{array}$ & 0,598 & 0,259 & 0,618 & 0,241 & 0,562 & 0,221 & 0,617 & 0,307 \\
\hline $\begin{array}{l}\text { the } 10 \text { main shareholders } \\
\text { Average number of shares }\end{array}$ & 45,699 & 14,027 & 48,110 & 15,449 & 45,925 & 13,523 & 44,007 & 13,449 \\
\hline $\begin{array}{l}\text { owned by the shareholders } \\
\text { Average } \% \text { of shares owned by }\end{array}$ & 8911,180 & 4629,332 & 7610,407 & 3893,465 & 9575,246 & 4656,827 & 9217,197 & 4924,611 \\
\hline $\begin{array}{l}\text { other firms } \\
\text { Average } \% \text { of shares owned by }\end{array}$ & 25,379 & 19,686 & 25,609 & 20,611 & 25,692 & 18,314 & 24,853 & 20,388 \\
\hline $\begin{array}{l}\text { foreign firms } \\
\text { Average } \% \text { of shares owned by }\end{array}$ & 6,697 & 12,332 & 3,413 & 6,709 & 6,948 & 8,887 & 8,779 & 17,206 \\
\hline $\begin{array}{l}\text { financial institutions } \\
\text { Average } \% \text { of shares owned by }\end{array}$ & 32,775 & 21,128 & 26,535 & 15,882 & 33,589 & 14,653 & 36,720 & 28,390 \\
\hline individual shareholders & 1,733 & 2,347 & 1,601 & 2,402 & 2,153 & 2,820 & 1,374 & 1,517 \\
\hline $\begin{array}{l}\text { Average ratio of the bank debt } \\
\text { owned by the Main Bank } \\
\text { Average \% of Exports in total }\end{array}$ & 0,27878 & 0,13744 & 0,26075 & 0,13808 & 0,28299 & 0,12737 & 0,28817 & 0,15509 \\
\hline sales & 21,604 & 18,816 & 18,788 & 17,912 & 20,972 & 18,173 & 25,501 & 20,366 \\
\hline $\begin{array}{l}\text { Average capital ratio } \\
\text { Average ratio of } R \& D\end{array}$ & 6,095 & 5,275 & 2,278 & 1,481 & 6,257 & 3,604 & 10,117 & 6,335 \\
\hline expenses to total sales & 4,992 & 3,459 & NA & NA & NA & NA & 4,992 & 3,459 \\
\hline
\end{tabular}


Table 4: Evolution of the share of the firms according to their size (number of employees) and their percentage in the total employment:

Table 4a: In 1970.

\begin{tabular}{|l|c|c|c|c|}
\hline $\mathbf{3}$ CATÉGORIES & NUMBER OF FIRMS & \% OF TOTAL & EMPLOYMENT & $\begin{array}{c}\text { \% OF } \\
\text { TOTAL }\end{array}$ \\
\hline$>\mathbf{1 0 0 0 0}$ & 14 & 11 & 441078 & 67,2 \\
\hline $\mathbf{1 0 0 0} \&<\mathbf{1 0 0 0 0}$ & 78 & 61,9 & 196146 & 29,9 \\
\hline$<\mathbf{1 0 0 0}$ & 34 & 27 & 18782 & 2,9 \\
\hline (including $<\mathbf{5 0 0})$ & $(11)$ & $(8,7)$ & $(3097)$ & $(0,47)$ \\
\hline total & 126 & 100 & 656007 & 100 \\
\hline
\end{tabular}

Table 4b: In 2001.

\begin{tabular}{|l|c|c|c|c|}
\hline $\mathbf{3}$ CATÉGORIES & NUMBER OF FIRMS & \% OF TOTAL & EMPLOYMENT & $\begin{array}{c}\text { \% OF } \\
\text { TOTAL }\end{array}$ \\
\hline$>\mathbf{1 0 0 0 0}$ & 13 & 10,3 & 400406 & 66,2 \\
\hline$>\mathbf{1 0 0 0} \&<\mathbf{1 0 0 0 0}$ & 65 & 51,6 & 180625 & 29,9 \\
\hline$<\mathbf{1 0 0 0}$ & 48 & 38,1 & 23742 & 3,9 \\
\hline (including < 500) & $(26)$ & $(20,6)$ & $(8086)$ & $(1,3)$ \\
\hline total & 126 & 100 & 604773 & 100 \\
\hline
\end{tabular}

Table 4c: Total employment and average size in 1970 and in 2001.

\begin{tabular}{|l|l|l|}
\hline & 1970 & 2001 \\
\hline Total Employment & 656007 & 604773 \\
\hline Average size & 5206 & 4800 \\
\hline Size Standard deviation & 12709 & 9941 \\
\hline
\end{tabular}

Figure 3: Evolution of the average size of the firms in 1970 and 2001 (balanced panel of 126 firms).

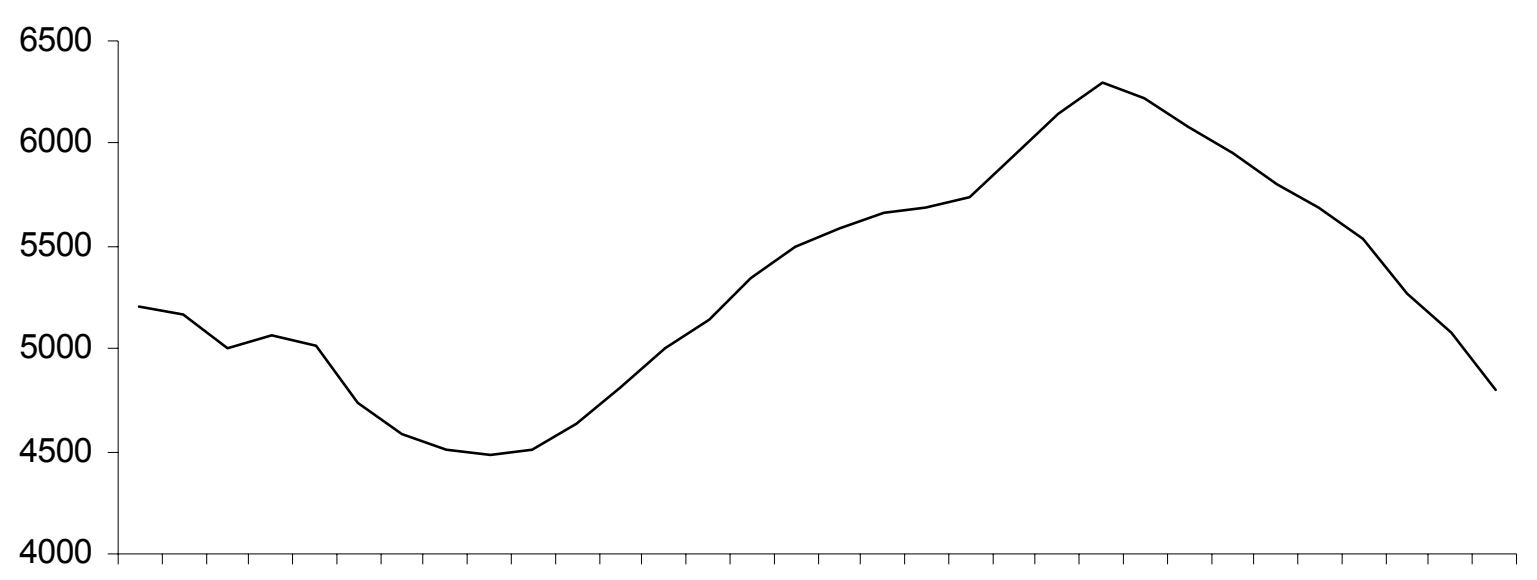

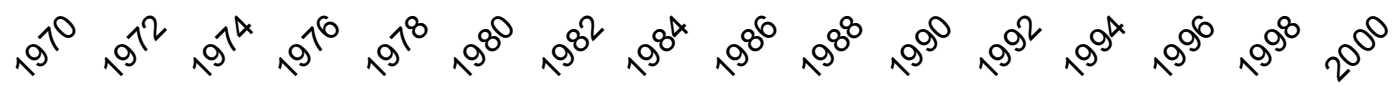


Figures 4: Profiles of employment adjustment and confrontation to the level of profits.

Hitachi (3)

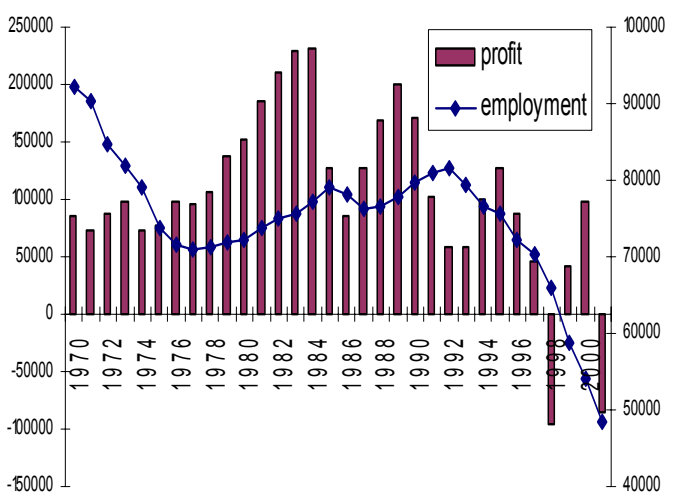

Togami Electric Mfg. (24)

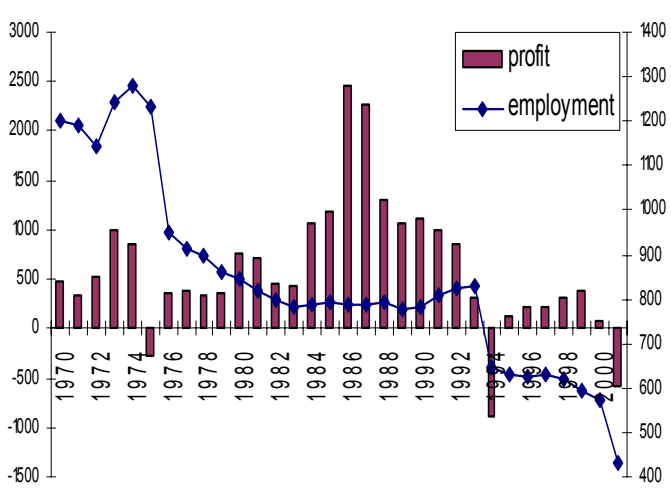

Nippon Columbia (68)

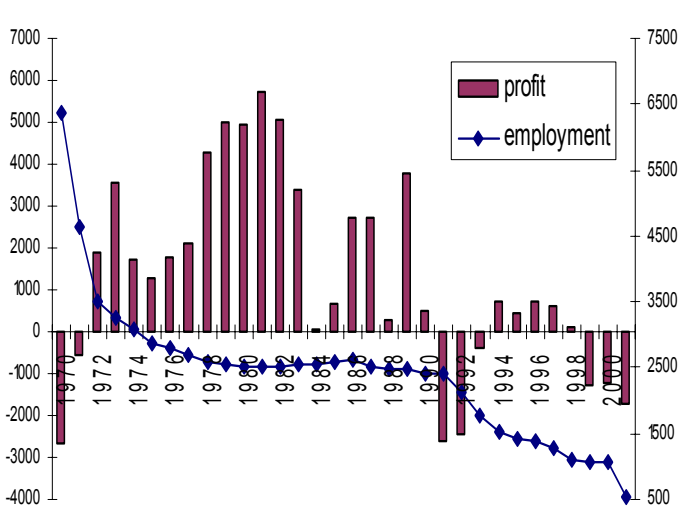

Yasukawa Electric (8)

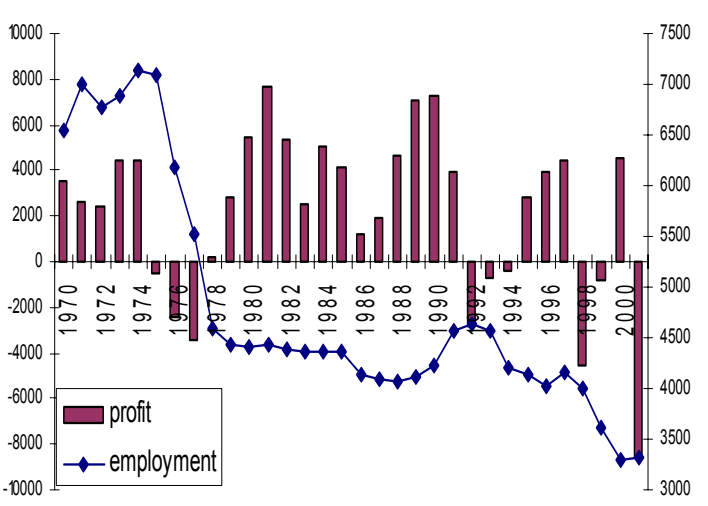

Kyushu Matsushita Electric (67)

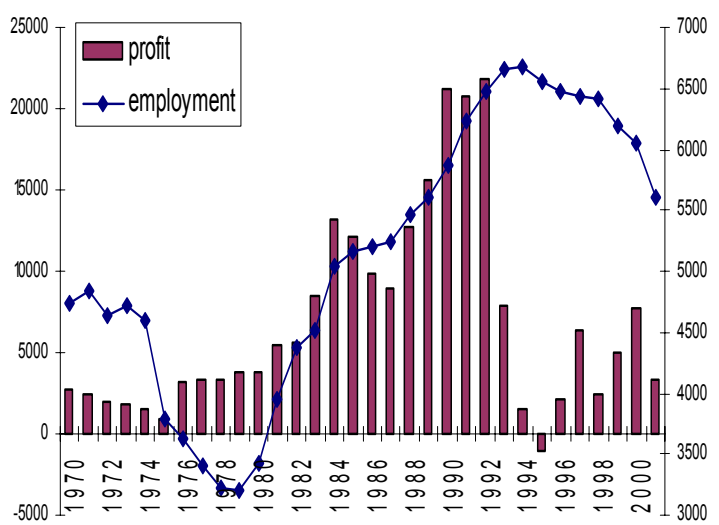

Nihon Inter Electronics (107)

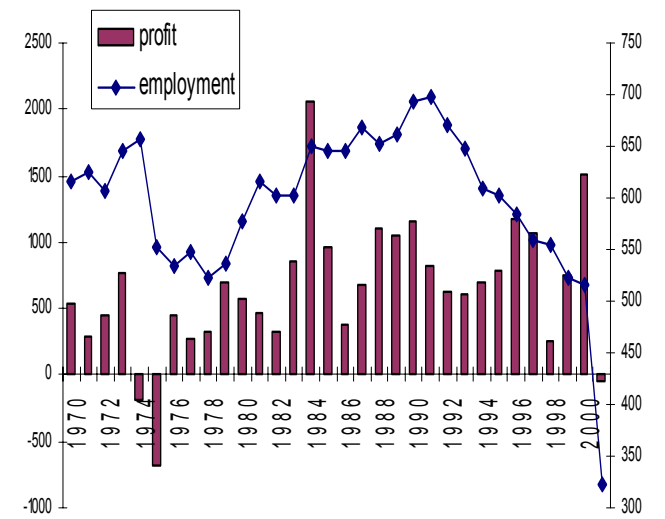


Table 5: Results of homogeneity tests.

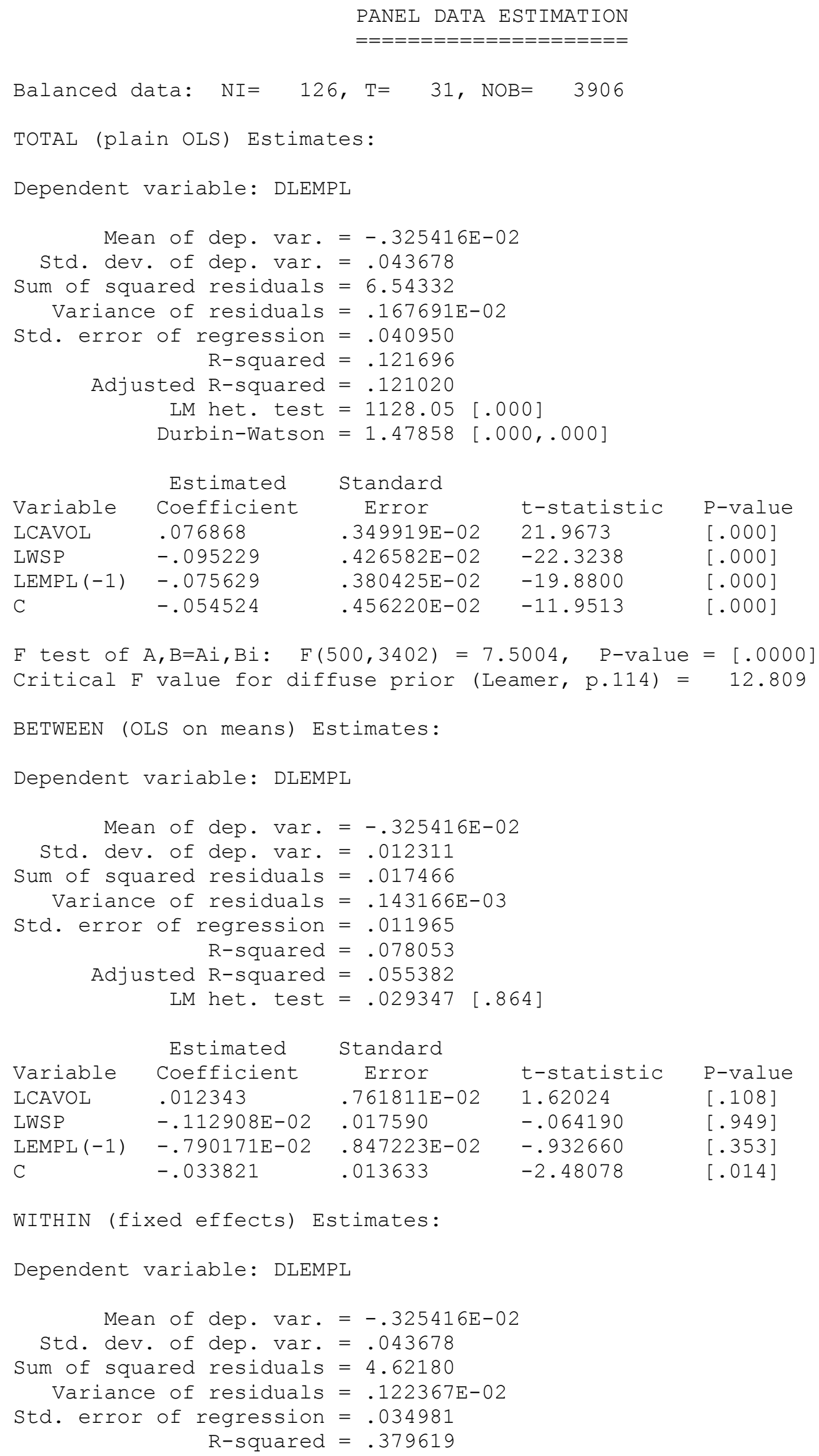




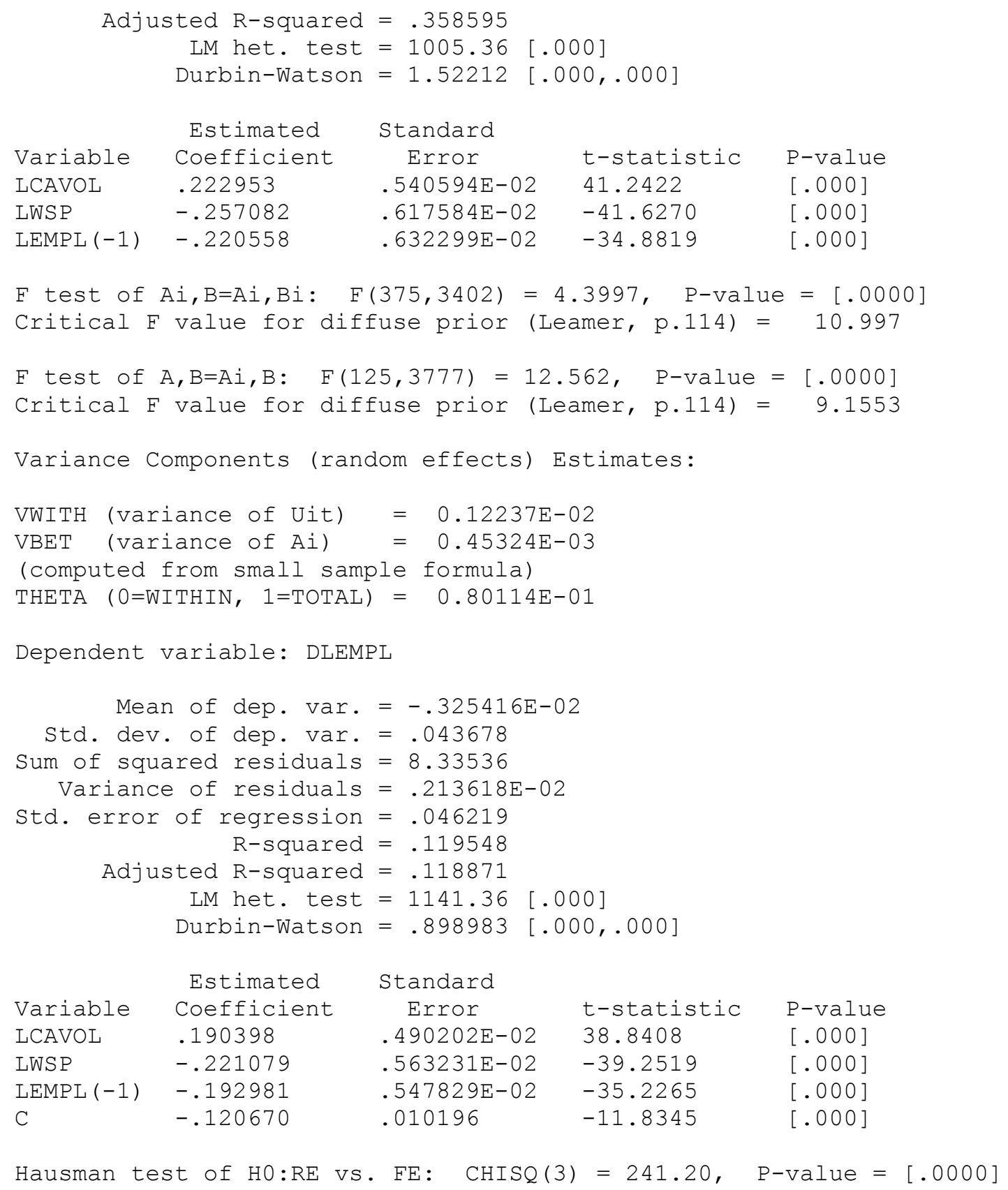


Table 6: Comparison between the estimation firm by firm and the panel estimation with random coefficients for a sample of firms (1971-1980).

\begin{tabular}{|c|c|c|}
\hline & speed estimated firm by firm & speed estimated with random coefficient model \\
\hline 1 & 0,503814876 & 0,549527764 \\
\hline 2 & 0,788410604 & 0,103869349 \\
\hline 3 & 0,579908788 & 0,244659796 \\
\hline 4 & 0,335423321 & 0,212699383 \\
\hline 5 & $-0,610420406$ & 0,177140415 \\
\hline 6 & 0,158761695 & 0,37319532 \\
\hline 7 & 0,706115842 & 0,209518746 \\
\hline 8 & 0,2789464 & 0,385567516 \\
\hline 9 & 0,433138579 & 0,357971907 \\
\hline 10 & 0,031673562 & 0,184404105 \\
\hline 11 & 0,332789004 & 0,325273365 \\
\hline 12 & 0,741884112 & 0,34700188 \\
\hline 13 & 0,574186504 & 0,432780266 \\
\hline 14 & 0,40429306 & 0,435788721 \\
\hline 15 & 0,659468174 & 0,367979258 \\
\hline 16 & 0,615445971 & 0,546907365 \\
\hline 17 & 0,396229029 & 0,358645976 \\
\hline 18 & 0,886071801 & 0,540623665 \\
\hline 19 & $-0,395223647$ & 0,27476117 \\
\hline 20 & $-0,973558784$ & 0,131500691 \\
\hline 21 & $-0,285983831$ & 0,208523706 \\
\hline 22 & 0,392286807 & 0,313024193 \\
\hline 23 & 0,66534996 & 0,247499391 \\
\hline 24 & 0,46842885 & 0,403247148 \\
\hline 25 & 0,575232863 & 0,428840607 \\
\hline 26 & 0,5556072 & 0,201883167 \\
\hline 27 & 0,663165689 & 0,304339886 \\
\hline 28 & 0,609350502 & 0,573274136 \\
\hline 29 & 1,020779014 & 0,301792204 \\
\hline 30 & 0,724712551 & 0,264116675 \\
\hline 31 & $-0,069236055$ & 0,278216362 \\
\hline 32 & 0,64308399 & 0,501812696 \\
\hline 33 & 0,47246176 & 0,547514081 \\
\hline 34 & 0,876112163 & 0,463701844 \\
\hline 35 & 0,989527464 & 0,48898837 \\
\hline 36 & 0,171299562 & 0,321011513 \\
\hline 37 & 0,446702749 & 0,438960671 \\
\hline 38 & 0,329988211 & 0,368725806 \\
\hline 39 & 0,958440304 & 0,74029249 \\
\hline 40 & 1,010483384 & 0,287351996 \\
\hline
\end{tabular}


Table 7: Results of the estimations (H1).

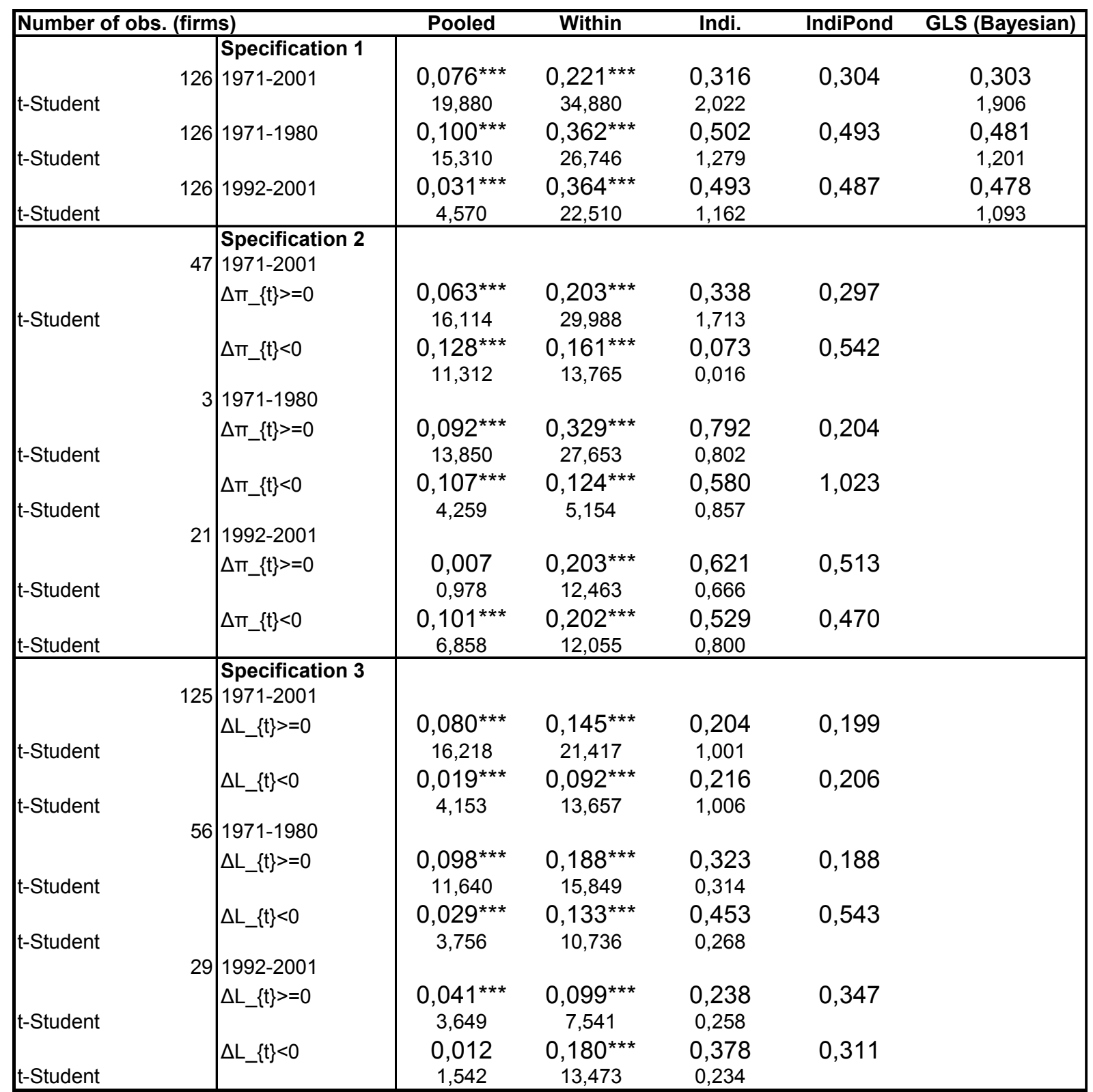

Note: The level of significance is given only for the pooled and within estimations ( * indicates a $10 \%$ significant level, ** 5\% and *** 1\%). As far the GLS estimations of the random coefficients model are concerned, we indicate only the realizations of the estimators of the mean and of the variance of the coefficients distribution. 
Figures 5: Evolution of the speed of employment adjustment (H1).

Figure 5a) Recursive method (within estimation).

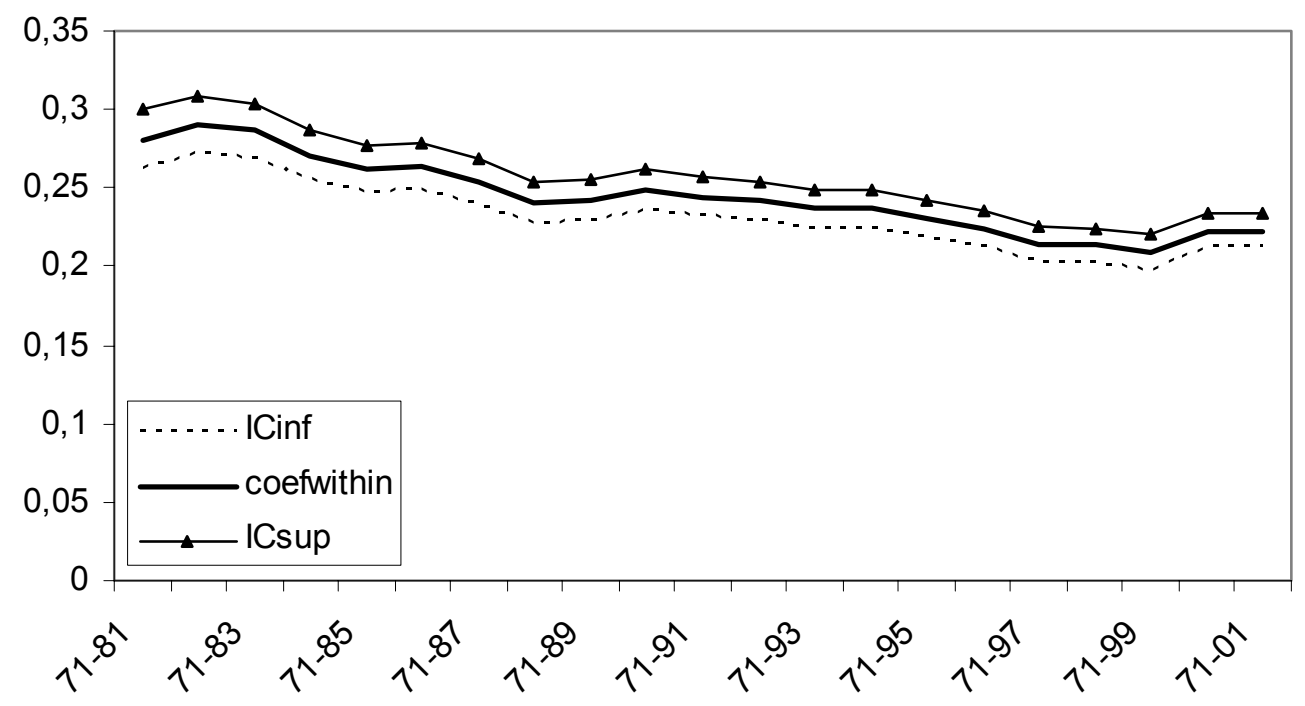

Figure 5b) Shifting method (within estimation).

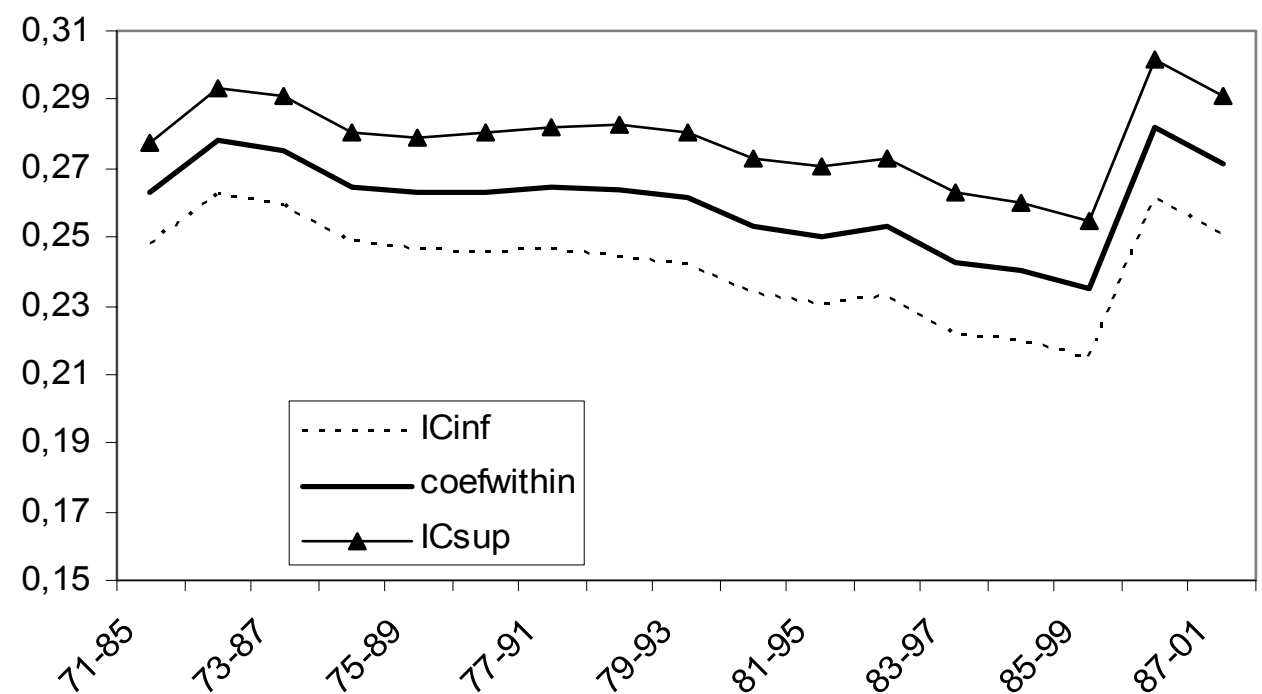

Note: The results obtained from the estimation of the model with random coefficients are similar. However, we present here the results from the within estimation because it gives the confidence interval, which is not possible in the case of the random coefficients model.

Table 8: A higher dispersion in the 1990s by comparison with the 1970s (H2a).

\begin{tabular}{|l|r|r|r|}
\hline Standard error & $1971-2001$ & $1971-1980$ & $1992-2001$ \\
\hline indi & 0,156444 & 0,39257 & 0,423749 \\
\hline MCG bay & 0,097394 & 0,149707 & 0,216672 \\
\hline
\end{tabular}


Figures 6: The changing distribution over time of the individual adjustment speeds (H2b).

$1^{\text {st }}$ sub-period: $1971-1980$

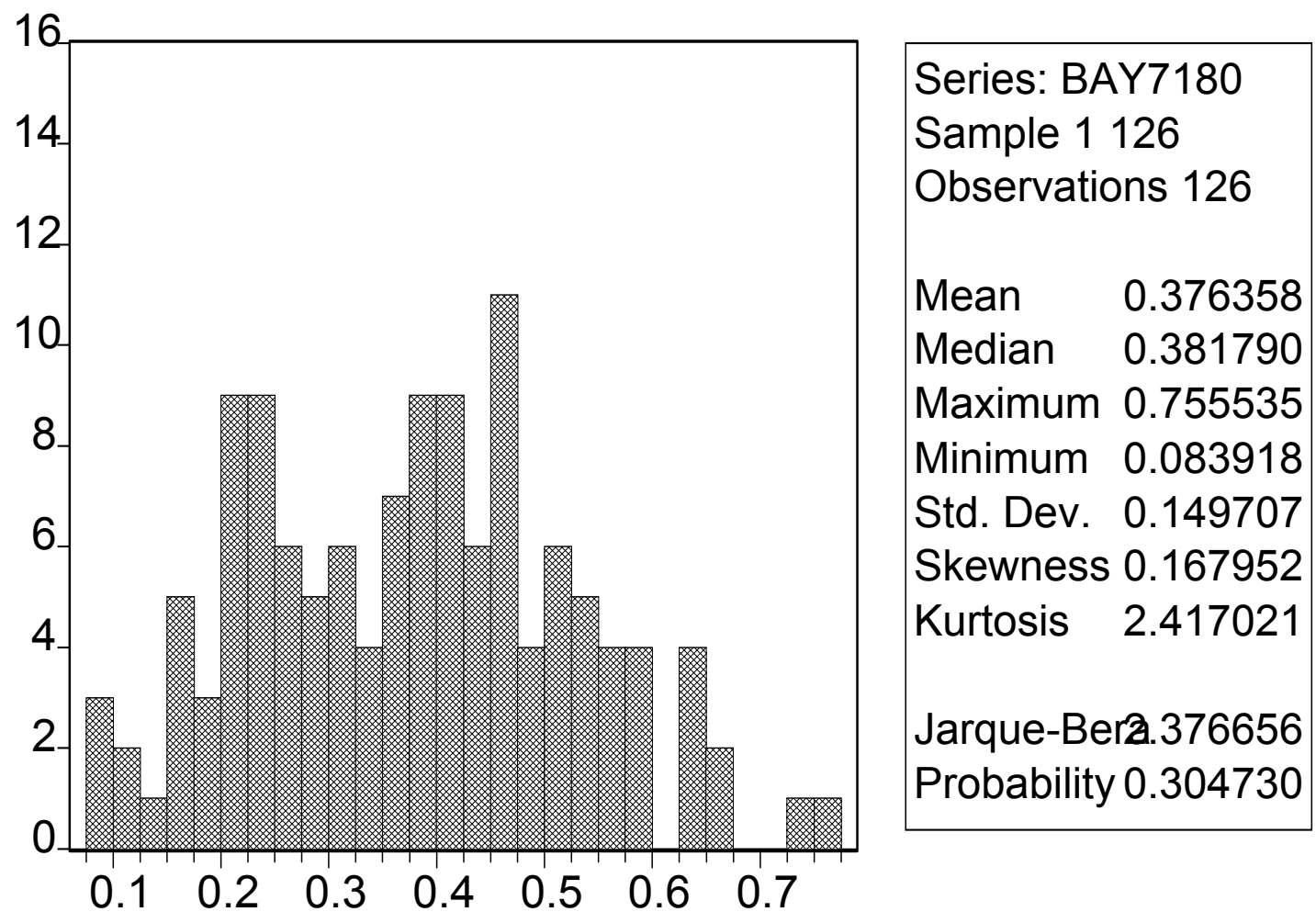

Kernel Density (Epanechnikov)

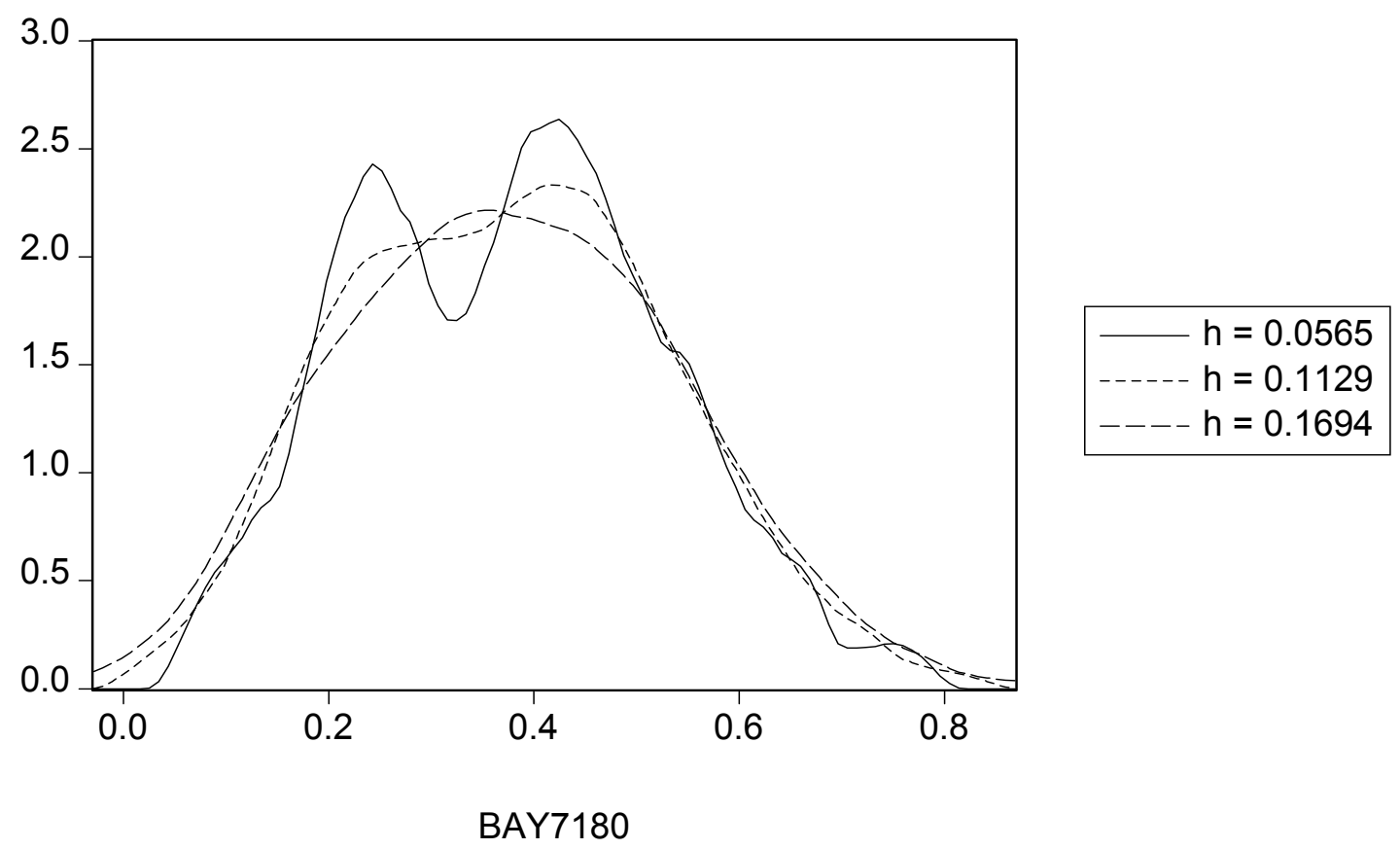




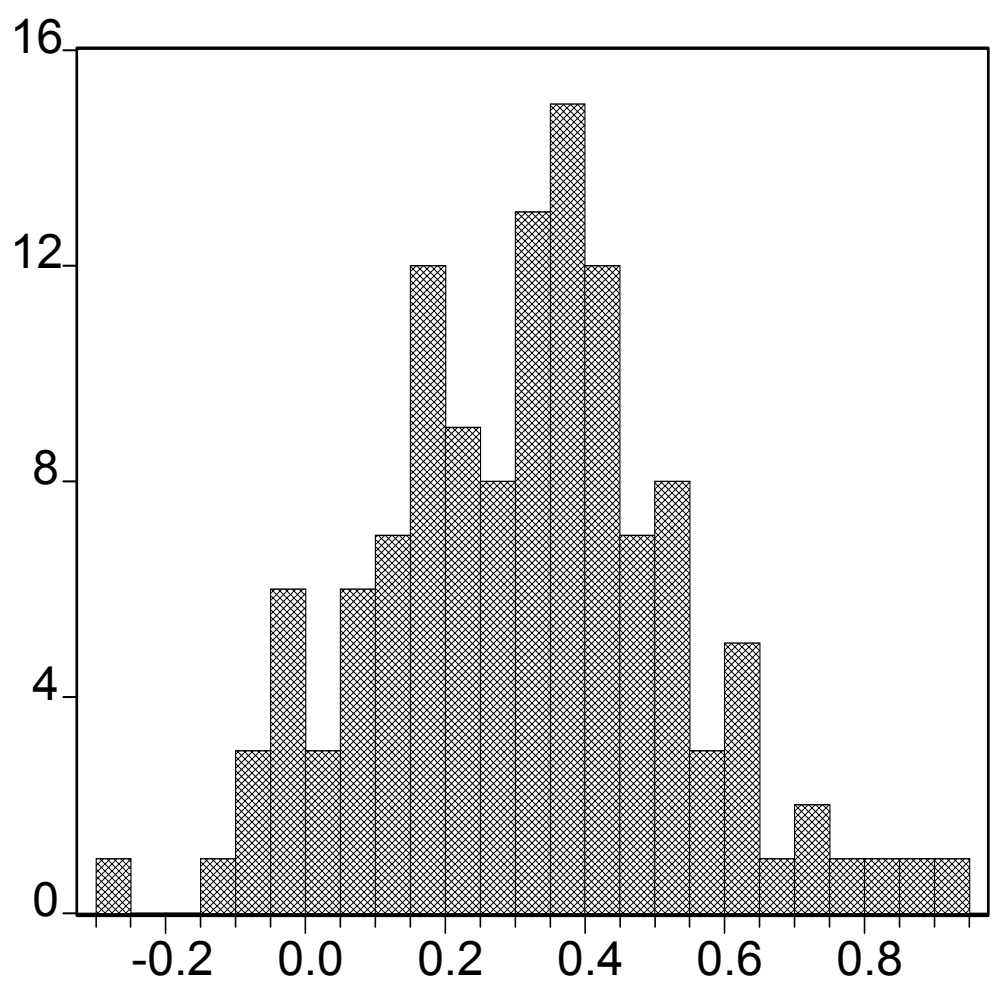

Series: BAY9201

Sample 1126

Observations 126

Mean $\quad 0.315927$

Median $\quad 0.322441$

Maximum 0.928113

Minimum $\quad-0.296006$

Std. Dev. 0.216672

Skewness 0.115149

Kurtosis $\quad 3.223564$

Jarque-Bera 0.540847

Probability 0.763056

Kernel Density (Epanechnikov)

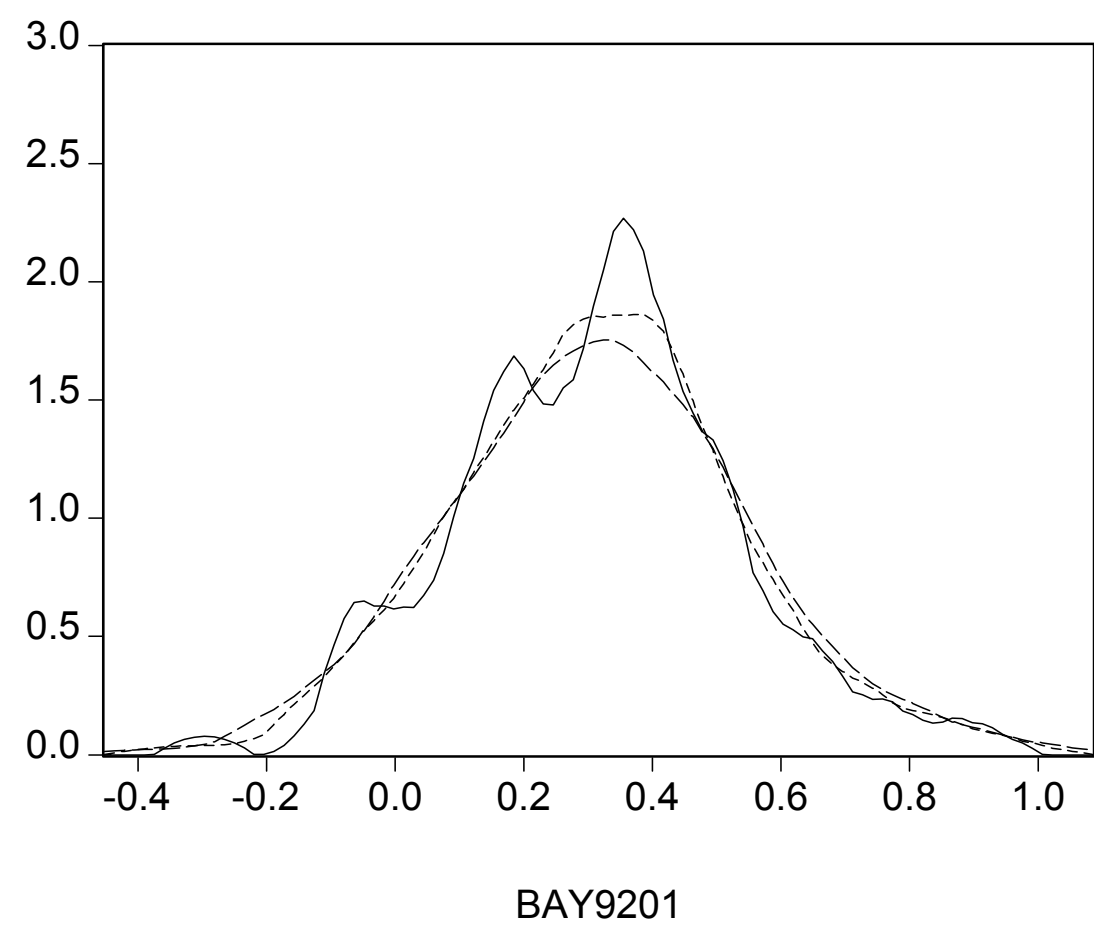

$\mathrm{h}=0.0779$

$\mathrm{h}=0.1558$

$\mathrm{h}=0.2337$

BAY9201 
Tables 9: The factors of the heterogeneity of the adjustment speed (H3).

Table 9a) 1971 - 2001.

\begin{tabular}{|c|c|c|c|c|}
\hline & Model 1 & Model 2 & Model 3 & Model 4 \\
\hline since_1 & $\begin{array}{c}.0004761 * * * \\
(3.768)\end{array}$ & $\begin{array}{c}.0007043^{* * *} \\
(4.579)\end{array}$ & $\begin{array}{c}.0000262 \\
(-0.146)\end{array}$ & \\
\hline misize1 & $\begin{array}{c}-1.98 \mathrm{e}-06 * * * \\
(-14.039)\end{array}$ & $\begin{array}{c}-2.43 \mathrm{e}-06^{* * *} * \\
(-15.025)\end{array}$ & $\begin{array}{c}-2.55 \mathrm{e}-06^{* * *} \\
(-13.241)\end{array}$ & $\begin{array}{c}-2.51 \mathrm{e}-06^{* * *} \\
(-14.363)\end{array}$ \\
\hline miagemo & $\begin{array}{c}.0042446 * * * \\
(6.088)\end{array}$ & $\begin{array}{c}.0049818 * * * \\
(5.594)\end{array}$ & $\begin{array}{c}.003228 * * * \\
(3.356)\end{array}$ & $\begin{array}{c}0032289^{* *} \\
(3.368)\end{array}$ \\
\hline miintK1 & $\begin{array}{c}.0013479 * * \\
(2.566)\end{array}$ & $\begin{array}{c}.0031836^{* * *} \\
(4.240)\end{array}$ & $\begin{array}{c}.0041196^{* * *} \\
(4.530)\end{array}$ & $\begin{array}{c}0038153 * * * \\
(4.725)\end{array}$ \\
\hline mirdrati & $\begin{array}{c}-.0034034 * * * \\
(-7.166)\end{array}$ & $\begin{array}{c}-.0061886^{* * *} \\
(-9.843)\end{array}$ & $\begin{array}{c}-.0083336 * * * \\
(-11.470)\end{array}$ & $\begin{array}{c}-.0086711 * * * \\
(-11.945)\end{array}$ \\
\hline mixprod & $\begin{array}{c}.0012377 * * * \\
(12.293)\end{array}$ & $\begin{array}{c}.0020686 * * * \\
(14.594)\end{array}$ & $\begin{array}{c}.0019016^{* * *} \\
(11.564)\end{array}$ & $\begin{array}{c}0019969 * * * \\
(12.130)\end{array}$ \\
\hline miroa & & $\begin{array}{c}-.0045775^{* * *} \\
(-4.084)\end{array}$ & $\begin{array}{c}-.0025091^{*} \\
(-1.814)\end{array}$ & \\
\hline miperf5 & & & & $\begin{array}{l}-.0026101 \\
(-2.381 \quad)\end{array}$ \\
\hline midbtpst & & & & $\begin{array}{c}-.0003193 * * * \\
(-2.620)\end{array}$ \\
\hline mider & & $\begin{array}{c}-.0001769 * * * \\
(-3.556)\end{array}$ & $\begin{array}{c}-.0002296 * * * \\
(-4.186)\end{array}$ & $\begin{array}{c}-.0002814 * * * \\
(-4.733)\end{array}$ \\
\hline midhk & & & $\begin{array}{c}.0578992 * * * \\
(3.686)\end{array}$ & $\begin{array}{c}.0726269 * * * \\
(4.539)\end{array}$ \\
\hline mishrco2 & & & $\begin{array}{c}.0026762 * * * \\
(8.028)\end{array}$ & $\begin{array}{c}.0028065^{* * *} \\
(8.336)\end{array}$ \\
\hline microshr & & & $\begin{array}{c}-.0021048 * * * \\
(-7.943)\end{array}$ & $\begin{array}{c}-.0021812^{* * *} \\
(-8.646)\end{array}$ \\
\hline miinstfi & & & $\begin{array}{c}-.0011024 * * * \\
(-4.981)\end{array}$ & $\begin{array}{c}-.0010825 * * * \\
(-5.464)\end{array}$ \\
\hline mifore11 & & & $\begin{array}{c}.0017429 * * * \\
(4.758)\end{array}$ & $\begin{array}{c}.0017462^{* * *} \\
(4.798)\end{array}$ \\
\hline miland & & & $\begin{array}{c}-.0009506 \\
(-0.863)\end{array}$ & \\
\hline mimb1 & & $\begin{array}{c}-.1699454 * * * \\
(-9.382) \\
\end{array}$ & $\begin{array}{c}-.1798288^{* * *} * \\
(-8.524) \\
\end{array}$ & $\begin{array}{c}-.1630135^{* * *} \\
(-7.767) \\
\end{array}$ \\
\hline cons & $\begin{array}{c}-.778545 * * * \\
(-3.083) \\
\end{array}$ & $\begin{array}{c}-1.167814^{* * *} \\
(-3.931) \\
\end{array}$ & $\begin{array}{c}.2342016 \\
(0.671) \\
\end{array}$ & $\begin{array}{c}.1653883 * * * \\
(4.030)\end{array}$ \\
\hline Adjusted-R ${ }^{2}$ & 0.1219 & 0.2191 & 0.2757 & 0.2768 \\
\hline Fisher & $F(6,3993)=93.50$ & $F(9,2870)=90.74$ & $F(15,2414)=62.63$ & $\mathrm{~F}(14,2415)=67.41$ \\
\hline $\mathrm{RSS}$ & 32.9045054 & 22.8051189 & 17.7926159 & 17.7724871 \\
\hline
\end{tabular}

Note: The t-Student are into brackets; * indicates a $10 \%$ significant level, ** 5\% and *** 1\% 
Table 9b) 1971-1980.

\begin{tabular}{|c|c|c|c|c|}
\hline & Model 1 & Model 2 & Model 3 & Model 4 \\
\hline since_1 & $\begin{array}{c}.0004609 \\
(1.112)\end{array}$ & & & \\
\hline misize1 & $\begin{array}{c}-1.84 \mathrm{e}-06^{* * *} \\
-4.788)\end{array}$ & $\begin{array}{c}-2.30 \mathrm{e}-06^{* * *} \\
(-5.381)\end{array}$ & $\begin{array}{c}-1.70 \mathrm{e}-06^{* * *} \\
(-4.470)\end{array}$ & $\begin{array}{c}-2.35 \mathrm{e}-06^{* * *} \\
(-5.555)\end{array}$ \\
\hline miagemo & $\begin{array}{c}-.0100684 * * * \\
(-5.136)\end{array}$ & $\begin{array}{c}-.0116943^{* * *} \\
(-6.080)\end{array}$ & $\begin{array}{c}-.0125497 * * * \\
(-7.418)\end{array}$ & $\begin{array}{c}-.0121353 * * * \\
(-6.343) \\
\end{array}$ \\
\hline miintK1 & $\begin{array}{c}.0338878 * * * \\
(7.347)\end{array}$ & $\begin{array}{c}.0339037 * * * \\
(7.388)\end{array}$ & $\begin{array}{c}.0362173 * * * \\
(8.961)\end{array}$ & $\begin{array}{c}.0355131 * * * \\
(7.736)\end{array}$ \\
\hline \multicolumn{5}{|l|}{ mirdrati } \\
\hline mixprod & $\begin{array}{c}.0015026^{* * *} \\
(5.109)\end{array}$ & $\begin{array}{c}.0015958 * * * \\
(5.076)\end{array}$ & $\begin{array}{c}.0015501 * * * \\
(5.433)\end{array}$ & $\begin{array}{c}.0015552 * * * \\
(4.987)\end{array}$ \\
\hline miroa & $\begin{array}{c}-.0077985^{* * *} \\
(-4.305) \\
\end{array}$ & $\begin{array}{c}-.0074366^{* * *} \\
(-4.496) \\
\end{array}$ & $\begin{array}{c}-.0062826^{* * *} \\
(-4.192) \\
\end{array}$ & \\
\hline miperf5 & & & & $\begin{array}{c}-.0092766^{* * *} \\
(-5.428)\end{array}$ \\
\hline midbtpst & $\begin{array}{l}.000487 \\
(1.332)\end{array}$ & & $\begin{array}{c}.0008486^{* * * *} \\
(2.805)\end{array}$ & \\
\hline mider & $\begin{array}{c}.0004268 * * * \\
(3.677)\end{array}$ & $\begin{array}{c}.0002587 * * * \\
(4.707)\end{array}$ & $\begin{array}{c}.0002655^{* * *} \\
(5.569)\end{array}$ & $\begin{array}{c}.0002472 * * * \\
(4.518)\end{array}$ \\
\hline midhk & $\begin{array}{c}-.2329115^{* * *} \\
(-7.323) \\
\end{array}$ & $\begin{array}{c}-.1463768^{* * *} \\
(-4.829) \\
\end{array}$ & $\begin{array}{c}-.1437099 * * * \\
(-5.433) \\
\end{array}$ & $\begin{array}{c}-.150491 * * * \\
(-5.121)\end{array}$ \\
\hline mishrco2 & & $\begin{array}{c}-.001364 * * * \\
(-3.979)\end{array}$ & & $\begin{array}{c}-.0015749 * * * \\
(-4.605) \\
\end{array}$ \\
\hline \multicolumn{5}{|l|}{ microshr } \\
\hline miinstfi & & $\begin{array}{c}-.0012968 \\
(-3.644) \\
\end{array}$ & $\begin{array}{c}-.0009822 * * * \\
(-3.237) \\
\end{array}$ & $\begin{array}{c}-.0012081 * * * \\
(-3.405) \\
\end{array}$ \\
\hline mifore11 & & & $\begin{array}{c}-.0018618^{* * *} \\
(-2.683)\end{array}$ & \\
\hline \multicolumn{5}{|l|}{ miland } \\
\hline mimb1 & $\begin{array}{c}-.0473551 \\
(-1.282)\end{array}$ & & & \\
\hline cons & $\begin{array}{c}-.0900478 \\
(-0.109) \\
\end{array}$ & $\begin{array}{c}.8995205 * * * \\
(11.904) \\
\end{array}$ & $\begin{array}{c}.8179596^{* * *} \\
(12.915) \\
\end{array}$ & $\begin{array}{c}.1653883 * * * \\
(4.030) \\
\end{array}$ \\
\hline Adjusted-R ${ }^{2}$ & 0.2624 & 0.3119 & 0.3180 & 0.3208 \\
\hline Fisher & $\mathrm{F}(10,957)=35.39$ & $F(9,686)=36.01$ & $F(10,909)=43.84$ & $F(9,686)=37.48$ \\
\hline RSS & 16.4271129 & 10.395825 & 13.767193 & 10.261378 \\
\hline
\end{tabular}

Note: The t-Student are into brackets; * indicates a 10\% significant level, ** 5\% and *** $1 \%$ 
Table 9c) 1992-2001

\begin{tabular}{|c|c|c|c|c|}
\hline & Model 1 & Model 2 & Model 3 & Model 4 \\
\hline since_1 & $\begin{array}{c}.0005543 \\
(1.157)\end{array}$ & $\begin{array}{c}.0016511 * * * \\
(3.528)\end{array}$ & $\begin{array}{c}.0022099 * * * \\
(4.064)\end{array}$ & $\begin{array}{c}.0024045^{* * *} \\
(4.851)\end{array}$ \\
\hline misize1 & $\begin{array}{c}-2.70 \mathrm{e}-06^{* * * *} \\
(-4.904)\end{array}$ & $\begin{array}{c}-1.77 \mathrm{e}-06^{* * *} \\
(-3.169)\end{array}$ & $\begin{array}{c}-7.66 \mathrm{e}-07 \\
(-1.145) \\
\end{array}$ & \\
\hline miagemo & $\begin{array}{c}.0151799 * * * \\
(6.906)\end{array}$ & $\begin{array}{c}.0078618^{* * *} \\
(3.493)\end{array}$ & $\begin{array}{c}.011724 * * * \\
(5.099)\end{array}$ & $\begin{array}{c}.0140228 * * * \\
(5.917)\end{array}$ \\
\hline miintK1 & $\begin{array}{c}.0052555^{* * *} \\
(5.096)\end{array}$ & & & \\
\hline mirdrati & $\begin{array}{c}-.0102352 * * * \\
(-5.378)\end{array}$ & $\begin{array}{c}-.0133813 * * * \\
(-7.103)\end{array}$ & $\begin{array}{c}-.0222025 * * * \\
(-9.011)\end{array}$ & $\begin{array}{c}-.0219663 * * * \\
(-8.993)\end{array}$ \\
\hline mixprod & $\begin{array}{c}-.0001593 \\
(-0.526)\end{array}$ & & & \\
\hline miroa & & $\begin{array}{c}-.0114485 * * * \\
(-4.407)\end{array}$ & $\begin{array}{c}-.0096603 * * * \\
(-3.160)\end{array}$ & \\
\hline miperf5 & & & & $\begin{array}{c}-.00264 * * \\
(-2.478)\end{array}$ \\
\hline \multicolumn{5}{|l|}{ midbtpst } \\
\hline mider & & & & $\begin{array}{c}-.0004483 * * * \\
(-4.619)\end{array}$ \\
\hline midhk & & $\begin{array}{c}.1109302^{* * *} \\
(4.374)\end{array}$ & & \\
\hline \multicolumn{5}{|l|}{ mishrco2 } \\
\hline microshr & & $\begin{array}{c}.0024727 * * * \\
(7.469) \\
\end{array}$ & $\begin{array}{c}.0038751 * * * \\
(9.240)\end{array}$ & $\begin{array}{c}.0045176^{* * *} \\
(10.460) \\
\end{array}$ \\
\hline \multicolumn{5}{|l|}{ miinstfi } \\
\hline mifore11 & & $\begin{array}{c}.0017738 * * * \\
(2.759)\end{array}$ & $\begin{array}{c}.0068092 * * * \\
(7.597)\end{array}$ & $\begin{array}{c}.0052122 * * * \\
(5.356)\end{array}$ \\
\hline \multicolumn{5}{|l|}{ miland } \\
\hline mimb1 & & & $\begin{array}{c}.1271186^{* *} \\
(-2.373)\end{array}$ & $\begin{array}{c}-.1722362 * * * \\
(-3.185)\end{array}$ \\
\hline _cons & $\begin{array}{c}-1.330699 \\
(-1.417) \\
\end{array}$ & $\begin{array}{c}-3.227516^{* * *} \\
(-3.516) \\
\end{array}$ & $\begin{array}{c}-4.372476^{* * * *} \\
(-4.157) \\
\end{array}$ & $\begin{array}{c}-4.832318^{* * *} \\
(-5.053) \\
\end{array}$ \\
\hline Adjusted-R ${ }^{2}$ & 0.1201 & 0.1774 & 0.2224 & 0.2346 \\
\hline Fisher & $\mathrm{F}(6,1243)=29.41$ & $\mathrm{~F}(8,1241)=34.67$ & $F(8,891)=33.13$ & $\mathrm{~F}(8,891)=35.44$ \\
\hline RSS & 50.9795235 & 47.5818466 & 31.0294962 & 30.5415276 \\
\hline
\end{tabular}

Note: The t-Student are into brackets; * indicates a 10\% significant level, ** 5\% and *** 1\%. 